\title{
Synthesis and spectroscopic characterization of novel GFP chromophore analogues based on aminoimidazolone derivatives
}

\author{
Attila Jancsó a , Ervin Kovács ${ }^{\text {b,c }}$, Levente Cseri c,d, Balázs Rózsa e,f, Gábor Galbács a , Imre G. \\ Csizmadia ${ }^{9}$ and Zoltán Mucsi ${ }^{c, e,{ }^{*}}$ \\ a Department of Inorganic and Analytical Chemistry, University of Szeged, Szeged H-6720, Hungary \\ b Institute of Materials and Environmental Chemistry, Research Centre for Natural Sciences, Hungarian Academy \\ of Sciences, $\mathrm{H}-1117$ Budapest, Hungary \\ c Department of Chemistry, Femtonics Inc., Budapest H-1094 Budapest, Hungary \\ a School of Chemical Engineering \& Analytical Science, The University of Manchester, Manchester, United \\ Kingdom \\ e Two-Photon Measurement Technology Research Group, The Faculty of Information Technology, Pázmány \\ Péter Catholic University, Budapest $\mathrm{H}$-1083, Hungary \\ ${ }^{f}$ Laboratory of 3D Functional Imaging of Neuronal Networks and Dendritic Integration, Institute of Experimental \\ Medicine, Hungarian Academy of Sciences, Budapest $H-1083$, Hungary \\ 9 Department of Chemistry, University of Toronto, Toronto, ON M5S 3H6, Canada. \\ *: Corresponding author at Department of Chemistry, Femtonics Inc., Tüzoltó utca 58, H-1094 Budapest, Hungary \\ E-mail address: zmucsi@femtonics.eu
}

\begin{abstract}
In order to improve the fluorescence properties of the green fluorescent protein chromophore, $p$-HOBDI ((5-(4-hydroxybenzylidene)-2,3-dimethyl-3,5-dihydro-4H-imidazol-4-one), sixteen dihydroimidazolone derivates were synthesized from thiohydantoin and arylaldehydes. The synthesis developed is an efficient, novel, one-pot procedure. The study provides a detailed description of the spectroscopic characteristics of the newly synthesized compounds, using $p$-HOBDI as a reference. The new compounds all exhibited significantly stronger fluorescence than $p$-HOBDI, up to 28 times higher quantum yields. An experimental and theoretical investigation of the relationship of the fluorescence properties with the molecular structure was also carried out. A good correlation was found between the emission wavenumber and the Hammett constant of the functional group, which suggests the intermolecular charge transfer (ICT) mechanism between the aromatic groups.
\end{abstract}
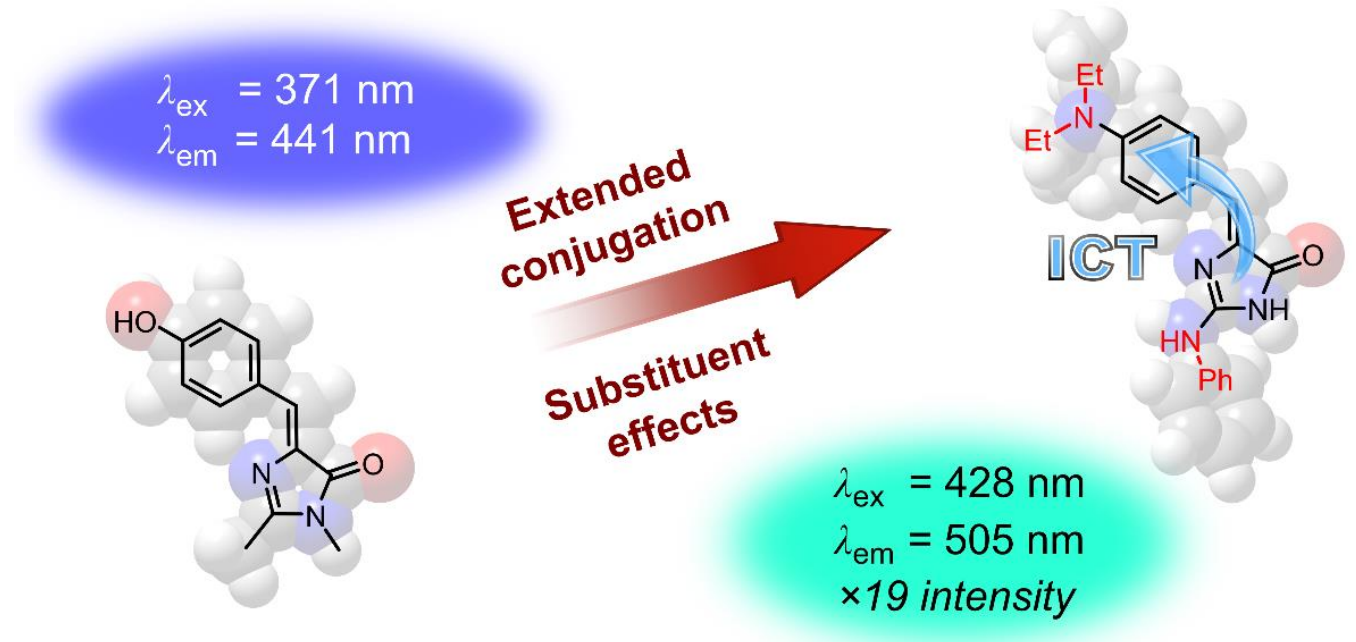

Graphical abstract 


\section{Introduction}

The green fluorescent protein (GFP), which is composed of 238 amino acid residues (ca. $26.9 \mathrm{kDa}$ ) and emits green light under excitation in the blue to ultraviolet range [1-3], can be isolated from several deep-sea organisms. GFP abbreviation stood for the protein isolated from the jellyfish Aequorea victoria $\left[\lambda_{\text {ex }}\right.$ (major) $=395 \mathrm{~nm}$ and $\left[\lambda_{\mathrm{ex}}(\right.$ minor $)=475 \mathrm{~nm} ; \lambda_{\mathrm{em}}=$ $509 \mathrm{~nm}$, quantum yield $(\mathrm{QY})=0.79$ ]. [2] The gene of GFP was frequently used as a reporter of expression in cellular and molecular biology [4] and is widely applied as such in many experiments with bacteria, yeast fungi, fish, plant, fly and mammalian, including human, cells [5-8].

The fluorophore in the center of these proteins contains a benzylidene-imidazolidinone moiety [9,10] (Figure 1) and it forms spontaneously from natural amino acids by cyclisation and subsequent oxidation [11,12]. According to literature data, its planar structure that includes a deprotonable 4-hydroxy group [11,12] can play an essential role in modifying the fluorescence properties of the macromolecule via the intramolecular excited-state proton transfer (ESPT) mechanism [13]. The protein environment is also known to have a dramatic influence on the emitted wavelength, via perturbing the polarity, $\mathrm{H}$-bonding property and aromatic $\pi$-interactions around the chromophore [14]. Some further post-translational modifications on the protein scaffold have also been shown to be capable of shifting the emission wavelength substantially. Fluorophores produced by such modifications are identified as red (RFP; Figure 1., lower line) $[15,16]$ orange and yellow [17-19], blue and cyan fluorescent proteins [20].

The chromophore formation mechanisms as well as the resulting fluorescent proteins were studied in a number of studies over the years. Their application fields are also numerous, including crystallography, biochemical studies of native and hydrolyzed fluorescent proteins, directed and random mutagenesis, and spectroscopy [21-27].

In an earlier study, the synthesis and photochemistry of the p-hydroxybenzylidene imidazolinone fluorophore (5-(4hydroxybenzylidene)-2,3-dimethyl-3,5-dihydro-4H-imidazol-4-one, or $p$-HOBDI, in Figure 1, upper line) and its close analogues were investigated [27]. Although $p$-HOBDI has an absorption peak near to that of GFP (ca. $375 \mathrm{~nm}$ ), its emission peak (around $440 \mathrm{~nm}$ ) and its quantum yield $\left(<10^{-4}\right)$ [27] are very far from those of the protein [28]. This observation raised the questions: what is the role of the protein around the chromophore and how can this environment increase the quantum yield (QY) up to 0.79 . This motivated the synthesis of a modified $p$-HOBDI scaffold which was found to exhibit improved fluorescence properties [29].

Previous synthesis efforts only aimed at synthesizing certain GFP analogues, such as $p$-HOBDI, by the systematic variation of the phenyl ring, but keeping the imidazolone part untouched. However, several $p$-HOBDI-analogue fluorophore moieties, substituted with conjugative groups at the imidazolone ring, were identified in the center of red fluorescent proteins (see e.g. HBMPDI in Figure 1, bottom line) and is taken responsible for the significant redshift and increased intensity of fluorescence [13]. Interestingly, these chromophores have not been individually synthesized and studied so far.

The goal of the present study was to enhance the fluorescence properties of $p$-HOBDI by substituting the original 5-methyl group with conjugative anilino-, benzylamino or thiobenzyl groups. This novel systematic structural modification of the $p$ HOBDI scaffold can further elucidate the reasons behind the differences in the emission intensities between the weakly fluorescing $p$-HOBDI and strongly fluorescing GFP. Earlier, this molecular scaffold was used intensively and successfully as glycine receptors [30] and kinase inhibitors [31], but no attention was paid to its spectroscopic properties. Here, we specifically intended to study the relationship between structure and fluorescence activity experimentally, and also by $a b-$ initio computations and calculation of Hammett constants. 


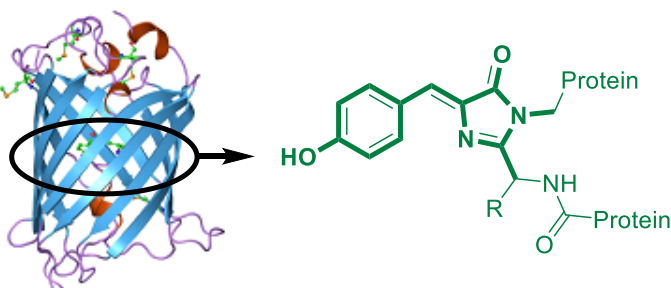

Green fluorescent protein (GFP)
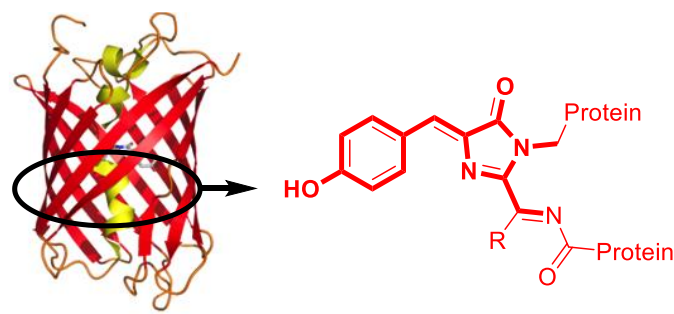

Red fluorescent protein (RFP)<smiles>C=CCCCOC(=O)OCCC1=NC(=Cc2ccc(O)cc2)C(=O)N1C</smiles>

p-HOBDI (synthesized)<smiles>[R]OC1=N/C(=C\c2[R1]cccc2)C(=O)N1[R]</smiles>

$\mathrm{R}^{2}=\mathrm{Ph}, \mathrm{Bn}$

$\mathrm{Q}=\mathrm{NH}, \mathrm{S}$

$\mathrm{R}^{3}=\mathrm{H}$ or $\mathrm{Me}$

1

Introduction of a new conjugative group

DsRed-like chromophore

(HBMPDI, not synthesized)

Figure 1. Structure of the $p-H O B D I$, chromophore of the green fluorescence protein (GFP, upper line) and HBMPDI, chromophore of the red fluorescence protein (RFP, bottom line). Model compound $\mathbf{1}$ is planned to combine the advantageous molecular features in new analogues.

\section{Experimental Section}

\subsection{UV/Vis spectra}

UV/Visible spectra were recorded on a Thermo Scientific Evolution 220 spectrophotometer in the wavelength range of $220-700 \mathrm{~nm}$ in a quartz cell with a pathlength of $1.0 \mathrm{~cm}$ equipped with a teflon stopper. The sample stock solutions were prepared by dissolving approximately $1-3 \mathrm{mg}$ of the compounds in $25.0 \mathrm{~mL}$ of the selected solvent (MeOH, DMSO, THF, MeCN, DCM), which was then adequately diluted with the same solvent to obtain solutions with concentrations of 10-80 $\mu \mathrm{M}$ suitable for recording the absorption spectra and for the determination of the wavelength of the absorption maxima $\left[\lambda_{\max }(\mathrm{ab})\right]$ and the related molar extinction coefficients $(\varepsilon)$.

\subsection{Fluorescence spectra}

Emission data were collected on a Hitachi F-4500 spectrophotometer at room temperature applying 5 and $10 \mathrm{~nm}$ slit widths for the excitation and emission beams, respectively, also performing background (solvent) correction. The sample solutions were prepared by dilution from stock solutions also used for the recording of the UV/Visible spectra. The final concentration of the solutions used for the fluorescence experiments varied in the concentration range of ca. 1-5 $\mu \mathrm{M}$. The samples were excited at (or close to) the absorption maxima $\left[\lambda_{\max }(\mathrm{em})\right]$, which were determined from the previously recorded UV/Vis spectra. The quantum yields were determined by the conventional method [32], using $p$-HOBDI as reference.

\subsection{Computational Methods}

All computations were carried out using the Gaussian09 program package (G09).[33] Geometry optimizations and subsequent frequency analyses were carried out at B3LYP/6-31G(d,p) level of theory.[34] Method and basis sets were chosen for their reliability in the characterization of aromaticity, in agreement with works published earlier.[35] The vibrational frequencies were computed at the same levels of theory as those used for geometry optimization, in order to properly confirm all structures as residing at minima on their potential energy hypersurfaces (PESs). Calculated (Table S1) and raw thermodynamic functions $U, H, G$ and $S$ (Tables S2S6) were computed at $298.15 \mathrm{~K}$, using the quantum chemical rather than the conventional, thermodynamic reference state. To model acetonitrile solvent, the IEF-PCM (integral equation formalism polarizable continuum medium) method was applied. The values for the enthalpy of hydrogenation $\left(\Delta H_{\mathrm{H} 2}\right)$ and the corresponding aromaticity of the aromatic rings were determined by earlier method [35] .The excited state optimization were carried out by time dependent (TD) DFT method [B3LYP/6-31G(d,p)], including the same solvent model.

\subsection{NMR spectroscopy}

The ${ }^{1} \mathrm{H}$ and ${ }^{13} \mathrm{C}$ NMR spectra were recorded on a Varian $500 \mathrm{MHz}$ spectrometer operating at $500 \mathrm{MHz}$ and $125 \mathrm{MHz}$, respectively in DMSO-d6 solvent.

\subsection{HPLC and HPLC-MS}

Accurate masses (HRMS) were determined with an Agilent 6230 time-of-flight high-resolution mass spectrometer. Sample introduction was performed by an Agilent 1260 Infinity LC system. The mass spectrometer was equipped with a Jet Stream electrospray ion source and operated in positive ion mode. Reference signals at $\mathrm{m} / z 121.050873$ and 922.009798 were used to calibrate the mass axis prior to analysis. 


\subsection{Infrared spectroscopy}

Infrared spectra were recorded on a Bruker Tensor 27 FT-IR instrument, by using the ATR method for powder samples.

\subsection{Sample purification}

In some cases, gradient elution preparative HPLC was applied (Armen) on a Gemini 250x50.00 mm; $10 \mu \mathrm{m}, \mathrm{C} 18,110 \mathrm{~A}$ column using $10 \mathrm{ml}$ of TFA in $5 \mathrm{I}$ water and acetonitrile as the two solvents.

\subsection{Synthesis}

All the starting materials, reagents and solvents were commercialized from Sigma Aldrich in reagent grade and used as received. NMR solvents were purchased from Eurisotop. HPLC solvents were from Merck.

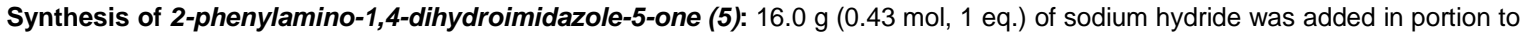

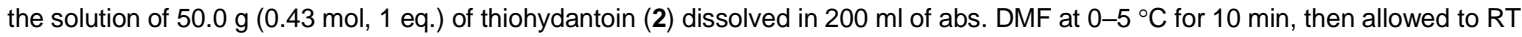
and the stirring was continued for $30 \mathrm{~min}$. The reaction mixture was cooled back to $0-5{ }^{\circ} \mathrm{C}$, then $24.0 \mathrm{~g}(0.41 \mathrm{~mol}, 0.95 \mathrm{eq}$. $)$ of Mel was added dropwise and stirred for $30 \mathrm{~min}$ at RT. Finally, $40.0 \mathrm{~g}(0.43 \mathrm{~mol} 1 \mathrm{eq}$.) of aniline (4) was added and stirred for $5-18 \mathrm{~h}$ at $100-110^{\circ} \mathrm{C}$. The conversion was followed by HPLC. The reaction mixture was poured into $300 \mathrm{ml}$ of icy-water and the solids formed were collected by filtration, washed with water and dried.

General procedure for synthesis of 5-arylmethylene-2-(phenylamino)-imidazolone derivatives (1a-p): The solution of $0.700 \mathrm{~g}$ of 2-anilino-1,5-dihydroimidazole-4-one (5, $4 \mathrm{mmol}, 1$ eq.), $4 \mathrm{mmol}$ of benzaldehyde derivative $6 \mathbf{a}-\mathbf{p}$ ( 1 eq.), and $200 \mu \mathrm{l}$ of pyrrolidine in $15 \mathrm{ml}$ of acetic acid was stirred at $110{ }^{\circ} \mathrm{C}$ for $1-3 \mathrm{~h}$. The conversion was followed by HPLC. The crude reaction mixture was evaporated to dry, then diluted with $\mathrm{EtOH}(6 \mathrm{ml})$ and solids were collected. When the purity was lower than $95 \%$ it was recrystallized from small amount of EtOH. In some cases, the product was purified by preparative HPLC. The fractions were collected, then filtered off or lyophilized.

Synthesis of 2-benzylamino-1,4-dihydroimidazole-5-one (8): $16.0 \mathrm{~g} \mathrm{(0.43} \mathrm{m,} 1$ eq.) of sodium hydride was added in portion to the solution of $50.0 \mathrm{~g}\left(0.43 \mathrm{~mol}, 1\right.$ eq.) of thiohydantoin (2), dissolved in $200 \mathrm{ml}$ of abs. DMF at $0-5^{\circ} \mathrm{C}$ for $10 \mathrm{~min}$, then allowed to RT

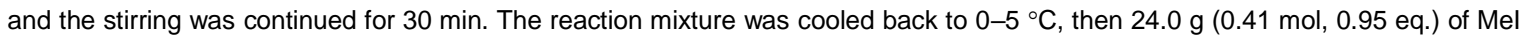
was added drop-wise and stirred for $30 \mathrm{~min}$ at RT. Finally, $0.43 \mathrm{~mol}$ (1 eq.) of benzylamine (7) was added and stirred for $18 \mathrm{~h}$ at 100 $110^{\circ} \mathrm{C}$. The conversion was followed by HPLC. The reaction mixture was poured into $300 \mathrm{ml}$ of ice-water and the solids formed were collected by filtration, washed with water and dried. Yield: $68 \%$; brown solids;

Synthesis of 5-(4-hydroxybenzylidene)-2-(benzylamino)-3,5-dihydro-4H-imidazol-4-one (9): The solution of $0.756 \mathrm{~g}$ of 2benzylamino-1,5-dihydroimidazole-4-one (7, $4 \mathrm{mmol}, 1$ eq.), $4 \mathrm{mmol}$ of 4-hydroxybenzaldehyde $6 \mathrm{a}$, (1 eq.) and $200 \mu \mathrm{l}$ of pyrrolidine in $15 \mathrm{ml}$ of acetic acid was stirred at $110{ }^{\circ} \mathrm{C}$ for $1-3 \mathrm{~h}$. The conversion was followed by HPLC. The crude reaction mixture was evaporated to dryness, then diluted with $\mathrm{EtOH}(6 \mathrm{ml})$ and solids were collected. It was recrystallized from small amount of EtOH. Yield: 63\%; yellow solids;

Synthesis of 5-(4-hydroxybenzylidene)-2-thioxoimidazolidin-4-one (10): The solution of $2.32 \mathrm{~g} \mathrm{(20} \mathrm{m} \mathrm{mol,} 1$ eq.) of thiohydantoin (2), $2.70 \mathrm{~g} \mathrm{(22} \mathrm{mmol)} \mathrm{of} \mathrm{4-hydroxybenzaldehyde} 6 \mathrm{a}$ and $500 \mu \mathrm{l}$ of pyrrolidine in $30 \mathrm{ml}$ of acetic acid was stirred at $110{ }^{\circ} \mathrm{C}$ for $18 \mathrm{~h}$. The conversion was followed by HPLC. The crude reaction mixture was purified by preparative HPLC. The reaction mixture was poured into $400 \mathrm{ml}$ of ice-water and the solids formed were collected by filtration, washed with water and dried. $3.3 \mathrm{~g}$ yellow solids;

Synthesis of 5-(4-hydroxybenzylidene)-2-(benzylthio)-3,5-dihydro-4H-imidazol-4-one (11): $400 \mathrm{mg}$ (10 mmol, 1 eq.) of sodium hydride $(60 \%)$ was added in portion to the solution of $2.2 \mathrm{~g}(10 \mathrm{mmol}, 1 \mathrm{eq}$.) of 5-(4-hydroxybenzylidene)-2-thioxoimidazolidin-4-one (10), dissolved in $30 \mathrm{ml}$ of abs. DMF at $0-5^{\circ} \mathrm{C}$ for $10 \mathrm{~min}$, then allowed to RT and the stirring was continued for $30 \mathrm{~min}$. The reaction mixture was cooled back to $0-5{ }^{\circ} \mathrm{C}$, then $1.60 \mathrm{~g}(9.5 \mathrm{~mol}, 0.95 \mathrm{eq}$.) of benzylbromide was added drop-wise and stirred for $60 \mathrm{~min}$ at RT. The reaction mixture was poured into $200 \mathrm{ml}$ of icy-water and the solids formed were collected by filtration, washed with water and dried. The crude product was purified by preparative HPLC. $1.58 \mathrm{~g}$; Yield: 51\%; pale solids.

\section{Results and Discussion}

\subsection{A new and efficient synthetic route for the preparation of $p$-HOBDI analogues}

Compounds 1a-p and $\mathbf{9}$ were synthesized in a new and efficient, two-step process (Scheme 1) and the derivatives were summarized in Table 1. Few compounds were already reported in the literature earlier (1e, 1i and 1j) $[36,37]$, but they were synthesized via multi-step procedures giving rise to poor yields. Moreover, none of these previous works assessed the photophysical properties of the compounds. In the present new, one-pot synthesis route, the thiohydantoin was methylated by $\mathrm{Mel}(\mathbf{2} \rightarrow \mathbf{3})$ then subjected to a subsequent nucleophilic substitution by an amino compound (4 or $\mathbf{7})$, furnishing imidazolone intermediates (5 or $\mathbf{8})$ with high yields. These intermediates finally readily took part in Knoevenageltype condensation with various aryl aldehydes 6a-p providing the final compounds (1a-p or 9) with high to moderate yields (62-87\%, in a mixture of $E$ and $Z$ isomers, with a $Z / E$ ratio of approximately $9 / 1)$. The benzylthio-imidazolone derivative (11) was synthesized in another way [38] where the Knoevenagel condensation with 6a was attained in the first step under conventional reaction conditions (Scheme 1). Following its isolation, 10 was subjected to the next alkylation step with benzyl bromide. This reaction condition was able to suppress the $O$ benzylation of 10 . The basic core of the GFP, $p$ HOBDI, was used as a reference compound during the fluorescence spectroscopy experiments. For this purpose, it was re-synthesized according to a procedure published earlier [27]. 


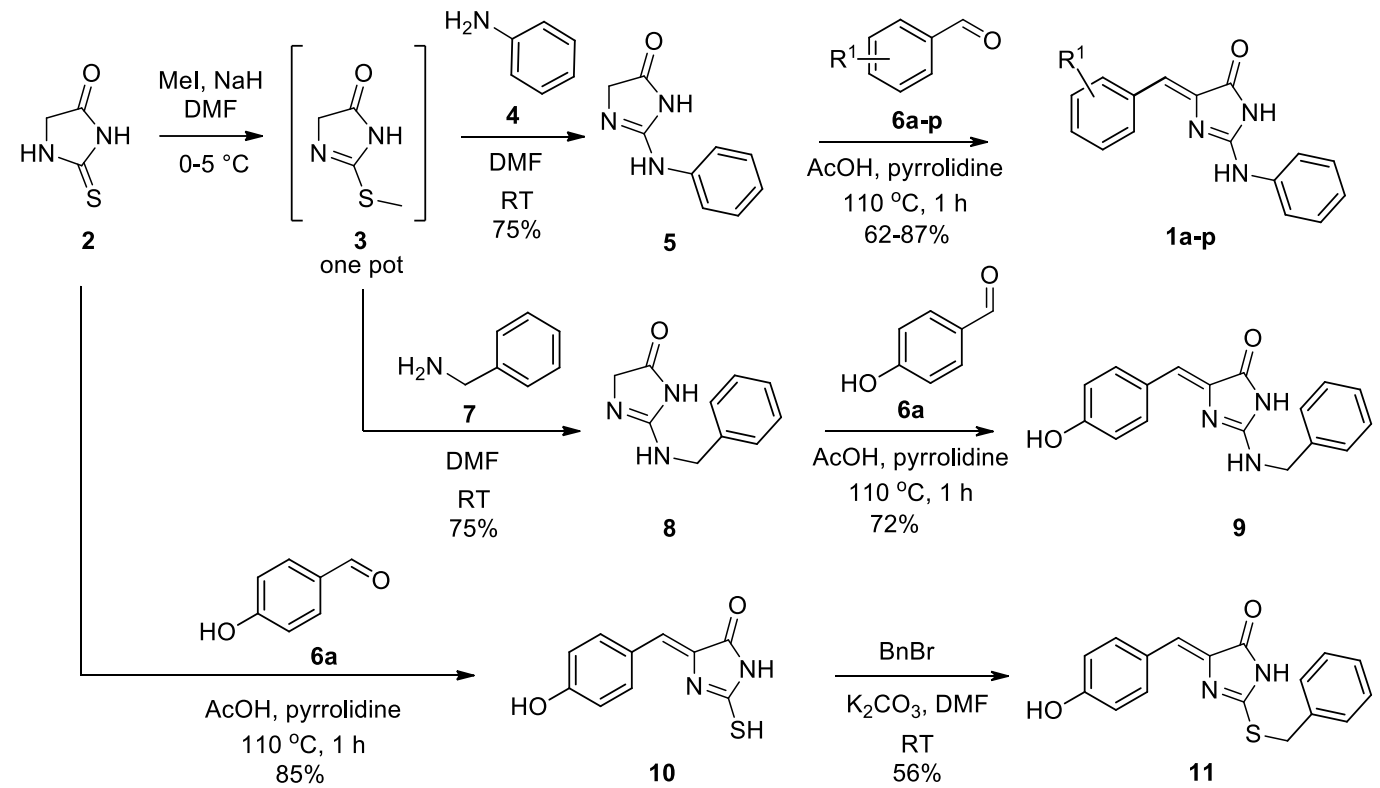

Scheme 1. The synthesis of substituted 4-benzylidene-2-(phenylamino)-imidazolones (1a-p) and 4-(4-hydroxybenzylidene)-2-(benzylamino)imidazolone (9) from 2-(phenylamino)-imidazolone (5) and 2-(benzylamino)-imidazolone (8), respectively, using various aldehydes 6a-p. Substituents indicated by $\mathrm{R}^{1}$ are listed in Table 1. The synthesis of 2-(benzylthio)-5-(4-hydroxybenzylidene)-imidazolone (11) from 2-mercaptoimidazolone (10) and benzyl bromide.

\subsection{General spectroscopic characterization}

All of the new compounds $(\mathbf{1} \mathbf{a}-\mathbf{p}$ and $\mathbf{9}, \mathbf{1 0}, \mathbf{1 1})$ exhibited enhanced fluorescence compared to the reference compound p-HOBDI. In all experiments, diluted solutions (1-5 $\mu \mathrm{mol} / / \mathrm{l}$ in $\mathrm{MeOH})$ of the compounds were used. The excitation wavelengths were set at (or close to) the position of the maxima of the absorption spectra and the emission spectra were recorded upwards from the wavelength of excitation until 600-700 nm. With the exception of only a couple of cases, the absorption spectra displayed two peaks, one around $250 \mathrm{~nm}$ and another between 370 and $430 \mathrm{~nm}$. The emission spectra, obtained by exciting the compounds at the latter absorption peak, showed a band of simpler shape, with maxima of medium or high intensities appearing between $440-550 \mathrm{~nm}$. In the minority of cases (see the supporting materials section), the absorption bands were composed of two, close $\left(\Delta \lambda_{\max } \sim 5-10 \mathrm{~nm}\right)$ absorption peaks around $380 \mathrm{~nm}$, indicating an equilibrium of $Z / E$ isomers. Excitation at both peaks resulted in the same emission spectra.

Spectroscopic properties of some, selected compounds were also studied in more polar (DMSO) and less polar (THF) solvents as well. Table 1 reflect our systematic efforts to generate structural situations where the substituents contribute significantly to the overall $\pi$-electronic distribution ( $R^{1}, R^{2}$ and $Q$ groups). In the following sections we provide a description and evaluation of the observed changes in the fluorescent properties induced by these substituents. During the evaluation, the fact that the basic 4-substituted-4-arylidene-5-imidazolinone scaffold can be represented by various resonance structures is also considered. 


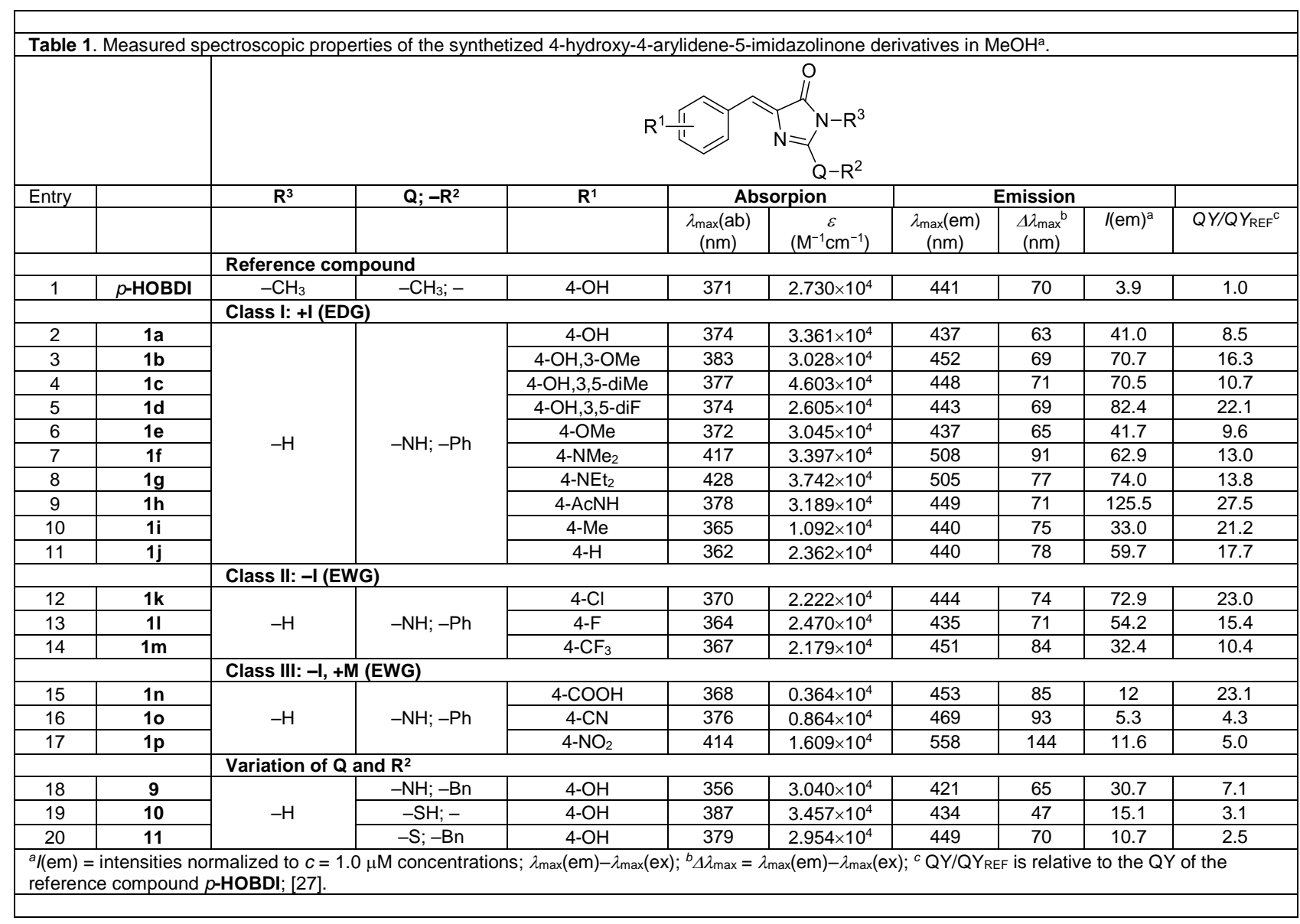

\subsubsection{Substituent effects}

\section{$R^{2}$ and $Q$ groups}

The direct comparison of the experimental spectroscopic data of $p$-HOBDI with its closest analog $1 \mathrm{a}$, recorded in $\mathrm{MeOH}$, reveals similar excitation (around $370 \mathrm{~nm}$, Table 1) and emission wavelengths (around $445 \mathrm{~nm}$ ). However, while $p$-HOBDI exhibits poor emission intensity in $\mathrm{MeOH}, \mathbf{1 a}$ (that simply replaces the 5 -methyl group with phenyl-substituted amino group) already shows a 10.5 times higher emission intensity as well as the QY is also increased significantly. We also found that the presence of the benzylamino group (9) could not boost further the emission intensity, as it only gave rise to a 7.9 relative intensity referenced to $p$-HOBDI. Excitation and emission wavelengths are also in the same ranges, which can be attributed to the enhanced intramolecular charge transfer [39], where the electron donating (ED) and conjugative character of the substituted amino group generate a higher electron density at the central imidazolone ring, illustrated in Scheme 2. At the same time, neither non-substituted nor substituted sulfur groups at the same position were successful to provide any significant ED effect, so the increase in relative intensity was much lower for them (Table $\mathbf{1}$ and $\mathbf{2}$ ).

$R^{1}$ group

As it was alluded to above, during the modifications of substituent $Q$, it became evident that aniline derivative 1a is a promising compound since it exhibits the highest emission intensity (relative to that of 1, 9, 10 and 11). Starting out from this finding, the systematic modifications were continued by altering the substituents of the phenyl ring $\left(R^{1}\right)$. As shown in Table 1, the various tested phenyl substituents could be sorted into three different classes (Class I-III) according to their electronic characters, which affect the fluorescence properties. The 2-(phenylamino)-imidazolone compounds 1a-I exhibited strong substituent effects. When electron donating groups (EDG) are present in compounds 1a-1i in para position, such as $\mathrm{OMe}, \mathrm{NEt}_{2}, \mathrm{OH}$, they were found to shift both the absorption peaks and emission wavelengths towards higher wavelength values compared to the non-substituted derivative (1j). The largest redshifts and intensities were observed for 4-amino derivatives, such as 4-NMe 2 (1f) and 4- $\mathrm{NEt}_{2}(\mathbf{1 g})$, presumably due to the fact that their ED effect is the strongest (Table 1) and 4-NHAc (1h) due to the electron lone-pair conjugation. This is supported by the observation that this effect can structurally stabilize the $S_{1}(o p t)$ state by one of its resonance structures, just after the excitation. This attractive improvement in the Stokes shift of amino compounds could be broken by acetylation. At the same time, the 
wavelength of the absorption and emission maxima for compound $\mathbf{1} \mathbf{h}$ is again near to the positions for $\mathbf{1} \mathbf{j}$, nevertheless, its relative emission intensity increases further, reaching the top value within the series.

Electron withdrawing groups (EWG) at the same position showed more complex effects. Depending on their mesomeric character, we sorted these into two classes. Non-conjugative EWGs, possessing only -I character, like $\mathrm{Cl}, \mathrm{F}$ and $\mathrm{CF}_{3}(\mathbf{1 k}$, $\mathbf{1 I}, \mathbf{1 m}$, in Class II) result in no significant changes in the position of the absorption and the emission maxima $(+5-10 \mathrm{~nm}$ shift) as well as their intensities remain relatively untouched compared to $\mathbf{1 j}$. In contrast to that, the conjugative EWGs ($\mathrm{I} ;+\mathrm{M}$ ) in Class III, such as $\mathrm{NO}_{2}(\mathbf{1 p}), \mathrm{CN}(\mathbf{1 0})$ and $\mathrm{COOH}(\mathbf{1 n})$ shift the emission wavelength higher, along with a drop in the wavelengths of absorption maxima and emission intensities. The molar absorption of compounds $\mathbf{1 n}-\mathbf{1 p}$ is tenfolds lower and the emission intensities are roughly equal to that of the reference molecule $p$-HOBDI.

From the aspect of applicability, the best properties are presented by compound $\mathbf{1 g}$, due to its high redshift and emission intensity of a single band at $505 \mathrm{~nm}$, when irradiated at $428 \mathrm{~nm}$ due to the ICT (Scheme 2, top). The Stokes shift is $77 \mathrm{~nm}$, moreover, the full width at half maximum of the fluorescent peak is only about $50 \mathrm{~nm}$. These two parameters satisfy the selective irradiation criteria, which means that there is no significant overlap between the emission and absorption bands. The most extreme effect was experienced for the $\mathrm{NO}_{2}$ (1p) group, which increased the excitation maximum to $414 \mathrm{~nm}$ and the emission maximum to $558 \mathrm{~nm}$, exhibiting the largest redshift, as well as the largest Stokes shift (144 nm), with moderate molar absorption and emission intensities. The highest Stokes shift can be explained by the ICT of nitro group (Scheme 2, bottom). The compound $1 \mathrm{~m}$ from Class II illustrates the situation where the ICT negligible (Scheme 2, middle).

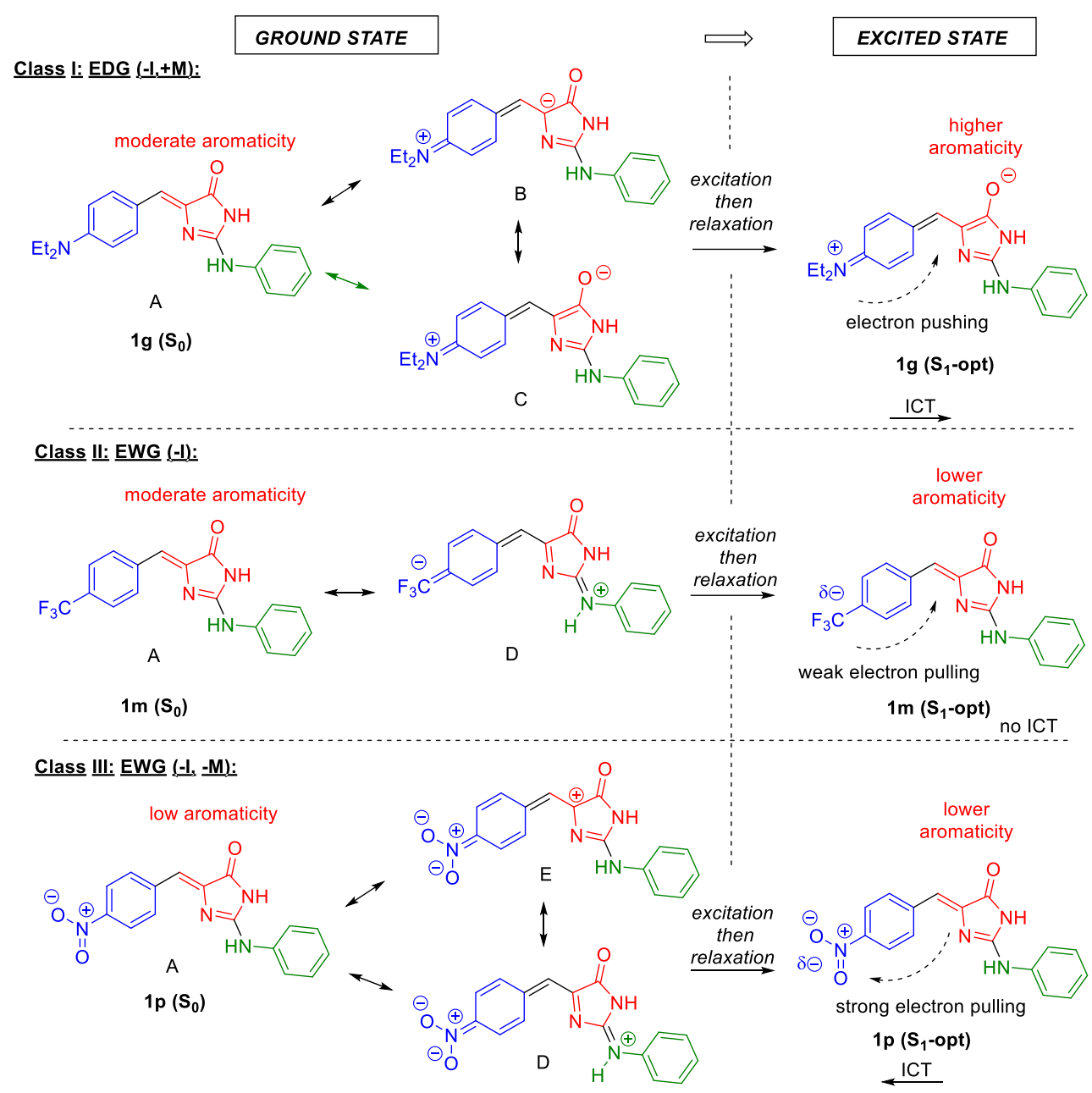

Scheme 2. Schematic illustration of the intramolecular charge transfer (ICT) process between electron rich and electron deficient regions for ground state structures in the compounds examined, ranking the compounds studied into three classes (Class I, II and III). 
The 4-monosubstituted derivatives (1a, 1e-1p) were also drawn into an examination of the correlation between their spectroscopic properties and their Hammett constants $\left(\sigma_{p} ;\right)$. Please note that wavenumbers are plotted in Figure 2 instead of wavelength values, due to the energy-related character of the former quantity [40]. In these plots, the data points (the position of both the excitation and emission peaks of these compounds as a function of their Hammett constants) were found to arrange along three separate trend lines (Line A, B and C in Figure 2, up) corresponding to the three substituent classes (Class I-III). Each category has a typical set of resonance structures, showed in Scheme 2. The wavenumbers for EDGs (Class I; 1a, 1e-1j; -I, +M) show an increasing trend (Line A), whereas for compounds with EWGs, two lines can be distinguished (Line $B$ and $C$ ). Class II includes functional groups having EWG properties (-I) without any significant conjugative effect, such as $\mathrm{Cl}(\mathbf{1 k}), \mathrm{F}(\mathbf{1 I})$ and $\mathrm{CF}_{3}(\mathbf{1 m})$, thereby resulting in data points lying along a line which is almost perfectly horizontal (Line B).

This indicates a nearly independent relationship between the two variables. Line $C$ represents the derivatives with EWGs possessing a strong conjugative character (Class III: 1n-p; $-\mathrm{I},-\mathrm{M})$, such as $\mathrm{COOH}(\mathbf{1 n}), \mathrm{CN}(\mathbf{1 0})$ or $\mathrm{NO}_{2}(\mathbf{1 p})$ groups, followed by a sharply decreasing trend, in contrast with Line A. Line A and C form a roof shape for both the excitation and emission wavenumbers, with crossing points near to the $\sigma_{p}$ values of hydrogen. Line $A$ and $C$ undoubtedly prove the dramatic role of the conjugative effect $(\mathrm{M})$ on the fluorescence wavenumber, in contrast to the non-conjugative groups (Line B).

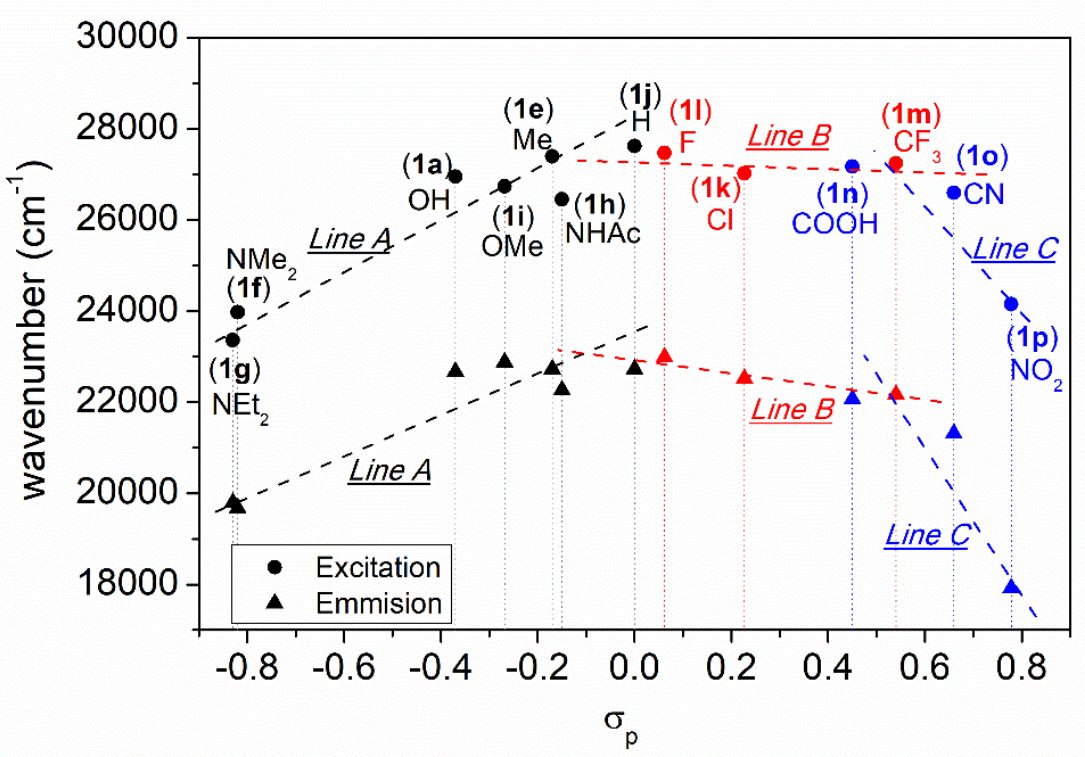

Figure 2. Correlation between Hammett constants $\left(\sigma_{p}\right)$ of the various substituents and the excitation (circle) as well as the emission (triangle) wavenumbers (in $\mathrm{cm}^{-1}$ ) for compounds 1a-1p ranked into three classes [Class I - black (Line A); Class II - red (Line B); Class III - blue (Line C)].

Aromaticity plays a crucial role in the process of the excitation. The central imidazolone ring (AR2, see Table 2) possesses a weakly anti-aromatic or non-aromatic character, as also indicated by aromaticity percentages (AR\%) [35,41,42] calculated for $p$-HOBDI, 1j, 1f, 1m, 1p (Table 2 and Figure 3). Only an EDG on the AR1 (Table 2), such as 4-NMe 2 (Class I) is able to generate a sufficient electron density in AR2 to reach a non-aromatic state. Not surprisingly, AR1 and AR3 are nearly fully aromatic. As expected, the 4-substitution on AR1 causes the largest aromaticity change. In each case, the aromaticity character of AR2 increases significantly $(+21.1$ to $+36.3 \%)$, depending on the electronic effect of substituent $\mathrm{R}^{1}$ (Table 2), restoring a weak aromaticity to this five-membered ring. EDGs (Class I) at position 4 of AR1 increase the $A R \%$ values of $A R 2$ more than EWGs. It may be more interesting to note that the aromaticity values for AR1 increase significantly by conjugative type functional groups, like $\mathrm{NMe}_{2}(+\mathrm{M} ;+19.8 \%)$ and $\mathrm{NO}_{2}(-\mathrm{M} ;+15.9 \%)$ at position 4 , irrespectively of their electronic effect. In contrast to this, aromaticity changes in other cases proved to be negligible (ca. $5 \%$ ). The importance of $-\mathrm{NH}-\mathrm{AR} 3$ is clearly shown here, this group decrease significantly the antiaromaticity of the AR2 in ground state and increase the aromaticity in excited state.

In compounds of Class II and III, a reverse situation is seen, namely the electron density migrates from AR2 to AR1, (which can be represented by resonance structures $\mathrm{D}$ or $\mathrm{E})$. It is to be noted however that the extent of the change is much larger in Class III (1p) and it is only symbolic in Class II (1m). The increased aromaticity character of AR1 and AR2 rings in $1 \mathbf{f f}$ and $1 p$ brought about a significant energy stabilization for these compounds during the excitation process and the consequent geometry relaxation. This results in a significant Stokes shift, as well as an elevated emission intensity. 


\begin{tabular}{|c|c|c|c|c|c|c|c|c|c|c|c|c|}
\hline \multicolumn{13}{|c|}{$\begin{array}{l}\text { Table 2. Calculated aromaticity percentage for the different aromatic rings (AR1, AR2 and } \mathrm{AR} 3 \text { ) of the } \\
\text { and 1p) in their different states. All computations were done at } \mathrm{B} 3 \mathrm{LYP} / 6-31 \mathrm{G}(\mathrm{d}, \mathrm{p}) \text { level of theory. }\end{array}$} \\
\hline \multirow[t]{2}{*}{ Compounds } & \multicolumn{2}{|c|}{ Substituents } & & \multicolumn{3}{|c|}{$\begin{array}{c}\text { Ground state } \\
\left(\mathrm{S}_{0}\right)\end{array}$} & \multicolumn{3}{|c|}{$\begin{array}{c}\text { Relaxed ex. state } \\
\left(\mathrm{S}_{1} \text {-opt }\right)\end{array}$} & \multicolumn{3}{|c|}{$\begin{array}{l}\text { Differences } \\
\left(\mathrm{S}_{0} \rightarrow \mathrm{S}_{1} \text {-opt }\right)\end{array}$} \\
\hline & $\mathbf{R}^{1}$ & $\mathbf{Q}$ & Class & AR1 & AR2 & AR3 & AR1 & AR2 & AR3 & $\Delta \mathrm{AR} 1$ & $\Delta \mathrm{AR2}$ & $\triangle \mathrm{AR3}$ \\
\hline$p$-HOBDI ${ }^{\mathrm{a}}$ & $\mathrm{H}$ & $\mathrm{Me}$ & ref & 107.5 & -16.9 & - & 106.8 & 7.3 & - & -0.7 & 24.2 & - \\
\hline $1 \mathrm{j}$ & $\mathrm{H}$ & $\mathrm{NH}-\mathrm{Ph}$ & 1 & 107.8 & -5.4 & 102.9 & 111.9 & 30.9 & 102.9 & 4.1 & 36.3 & 0.0 \\
\hline 1f & $\mathrm{NMe}_{2}$ & $\mathrm{NH}-\mathrm{Ph}$ & 1 & 114.9 & -1.1 & 103.4 & 139.5 & 34.2 & 103.3 & 19.8 & 35.3 & -0.1 \\
\hline $1 \mathrm{~m}$ & $\mathrm{CF}_{3}$ & $\mathrm{NH}-\mathrm{Ph}$ & II & 103.8 & -7.2 & 102.9 & 109.1 & 21.2 & 102.4 & 5.3 & 28.4 & -0.5 \\
\hline $1 p$ & $\mathrm{NO}_{2}$ & $\mathrm{NH}-\mathrm{Ph}$ & III & 107.2 & -8.6 & 102.3 & 127.5 & 12.4 & 99.7 & 20.3 & 21.1 & -2.7 \\
\hline
\end{tabular}

$\square A R 1 \quad \square A R 2 \quad \square A R 3 \quad \square$ changes $S_{0} \rightarrow S_{1}$-opt

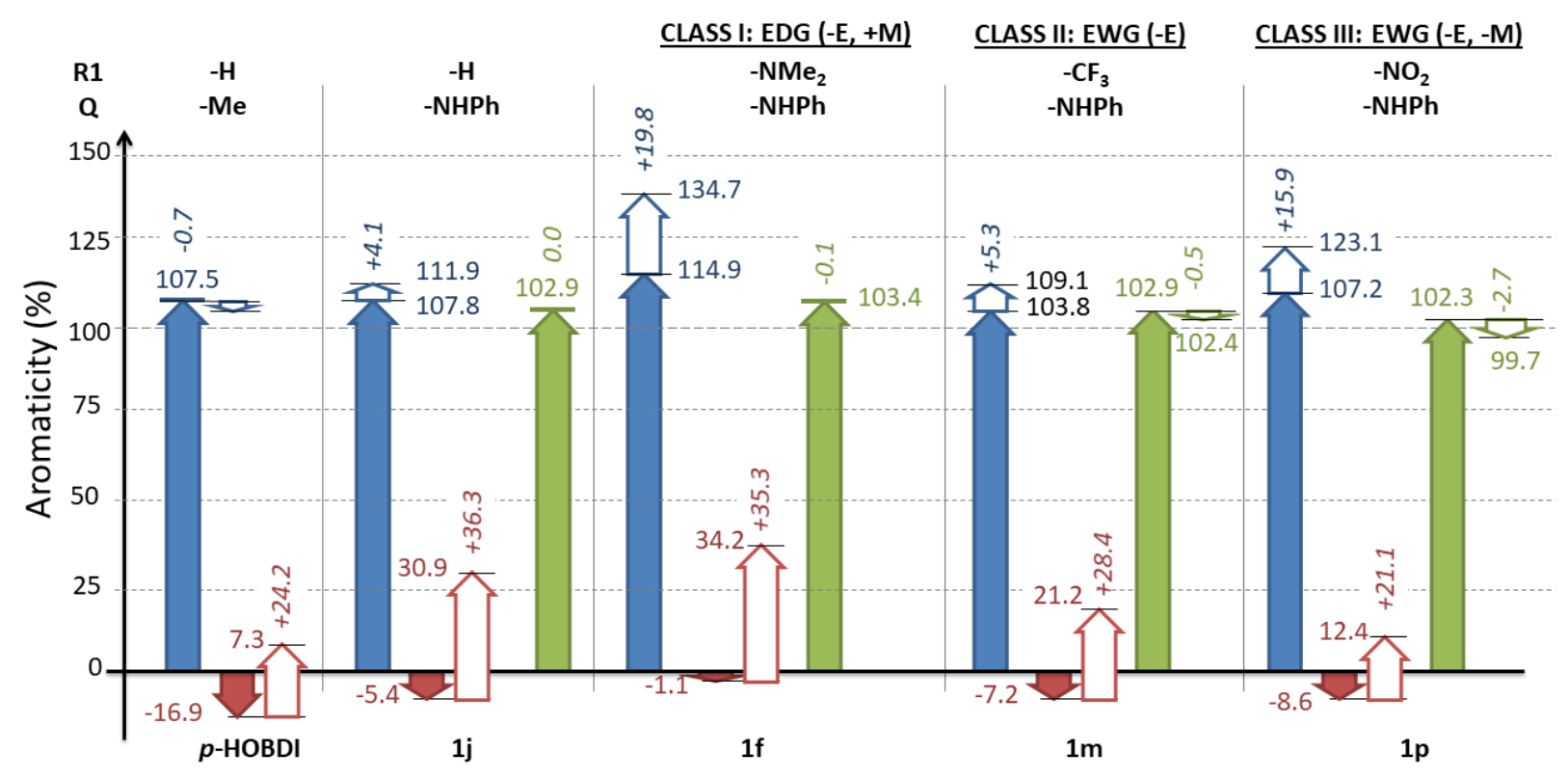

Figure 3. Bar representation of the changes of aromaticity percentages calculated for the three different aromatic rings (AR1 - blue, AR2 - red and AR3 - green, see in Table 2) of $p$-HOBDI, 1j, 1f, $1 \mathbf{m}$ and $\mathbf{1 p}$. The changes in aromaticity in the course of the excitation and a consequent geometry relaxation $\left[S_{0} \rightarrow\left(S_{1}\right) \rightarrow S_{1}\right.$-opt] are illustrated by the empty arrows with the same color. EDG = electron donating group; EWG = electron withdrawing group. All computations were done at B3LYP/6-31G(d,p) level of theory.

\subsubsection{Effect of the medium}

Photophysical properties, such as fluorescence emission, of many fluorophores are sensitive to the polarity of the solution environment and their variations can shed light onto fine intramolecular processes, such as intramolecular charge transfer, aromatization, bond strengthening/weakening or double bond rearrangements. The presence of hydrogen bond is also responsible for many photophysical and molecular properties [43][32]. For this reason, we briefly also studied the effect of the media ( $\mathrm{pH}$ and polarity) on the fluorescence features of some selected compounds.

\section{Acids or bases in MeOH solution}

Protonation of the tertiary amine function drastically alters the electron-donating properties of the tertiary amine group and consequently it is expected to switch off ICT [39]. Consequently, the emission spectrum of $\mathbf{1 g}$ was recorded for a series of $\mathrm{MeOH}$ solutions in which an increasing $\mathrm{HCl}$ concentration was present. The strong yellow color became significantly less intense even to the naked eye, due to the blueshift both in the absorption and emission spectra, accompanied by a reduced emission intensity. This process can be attributed to the protonation of the $\mathrm{NMe}_{2}$ group $\left(\mathbf{1 f} \rightarrow \mathbf{1 f}+\mathrm{H}^{+}\right.$, Scheme $\mathbf{3}$, bottom), which consequently flips from an EDG status to an EWD status. Acidifying the $\mathrm{MeOH}$ solvent decreases absorption at the original band at $440 \mathrm{~nm}$, while a new band emerges with a maximum at $325 \mathrm{~nm}$, as a function of acid 
concentration, as shown in Figure 4A. Varying the acid concentration also gives rise to two well-defined isosbestic points at 293 and $368 \mathrm{~nm}$. The lowest-energy absorption band of the ammonium form of the dye is blue-shifted by about $115 \mathrm{~nm}$ with respect to that of the neutral amine form (1f). The fluorescence emission spectra of $\mathbf{1 f}$ in $\mathrm{MeOH}$ also changes dramatically. The large emission peak at $511 \mathrm{~nm}\left(\lambda_{\mathrm{exc}}=420 \mathrm{~nm}\right)$ is blue-shifted to around $400 \mathrm{~nm}\left(\lambda_{\mathrm{exc}}=335 \mathrm{~nm}\right)$ at high $\mathrm{HCl}$ concentrations, as shown in Figure 4B.

The influence of alkaline conditions was studied for compound 1a. Deprotonation of the hydroxyl function at position 4 (1a $\rightarrow$ 1a- $\mathrm{H}^{+}$, Scheme 3, up and Figure 5A) increases the electron-donating properties of the aryl ring. As a result of this, an enhanced ICT could be expected for the addition of a strong base $(\mathrm{NaOH})$ to the methanolic solution of 1a. Indeed, a red shift of the emission peak (from $370 \mathrm{~nm}$ to $408 \mathrm{~nm}$ ) was observed, as is shown in Figure 5A. One isosbestic point (at 390 $\mathrm{nm}$ ) was identified as a function of the increasing base concentration. The fluorescence emission peak of 1a at $420 \mathrm{~nm}$ (excited at $370 \mathrm{~nm}$ ) in a base-free $\mathrm{MeOH}$ solution exhibits an intensity increase (ca. 50\%) and a red shift to $470 \mathrm{~nm}$ in a basic environment (Figure 5B). Nevertheless, the addition of triethylamine could not induce a similar change in the excitation and emission spectra of $\mathbf{1 a}$.

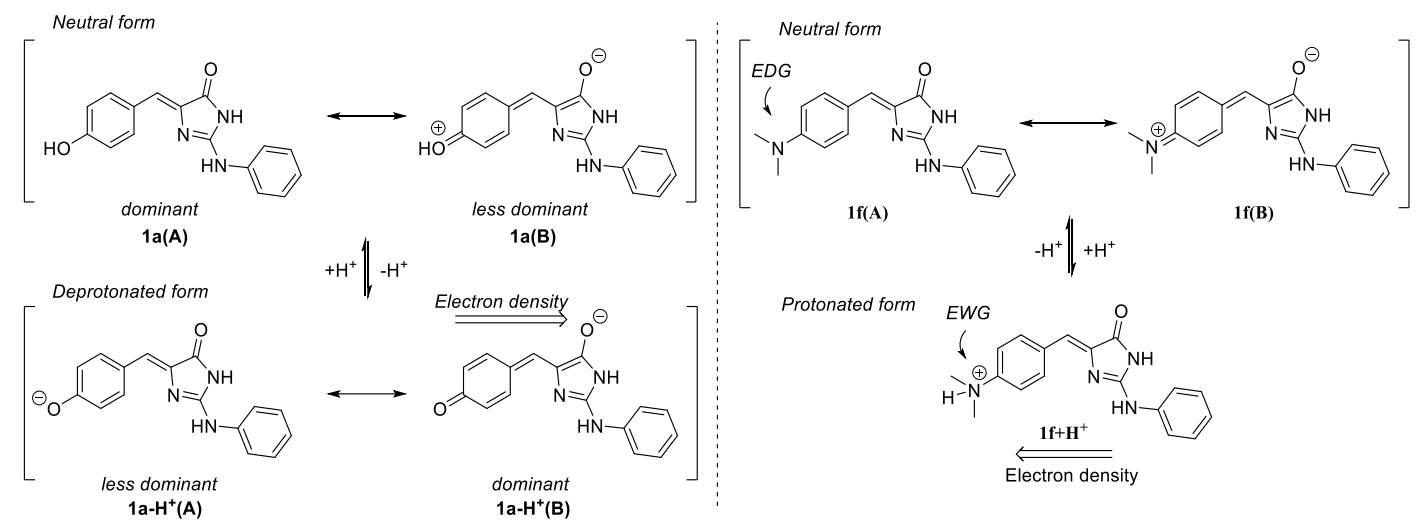

Scheme 3. The most dominant resonance structures (A, B) of $\mathbf{1 a}$ (left) in neutral and protonated forms, and $\mathbf{1 f}$ (right) in neutral and deprotonated forms.
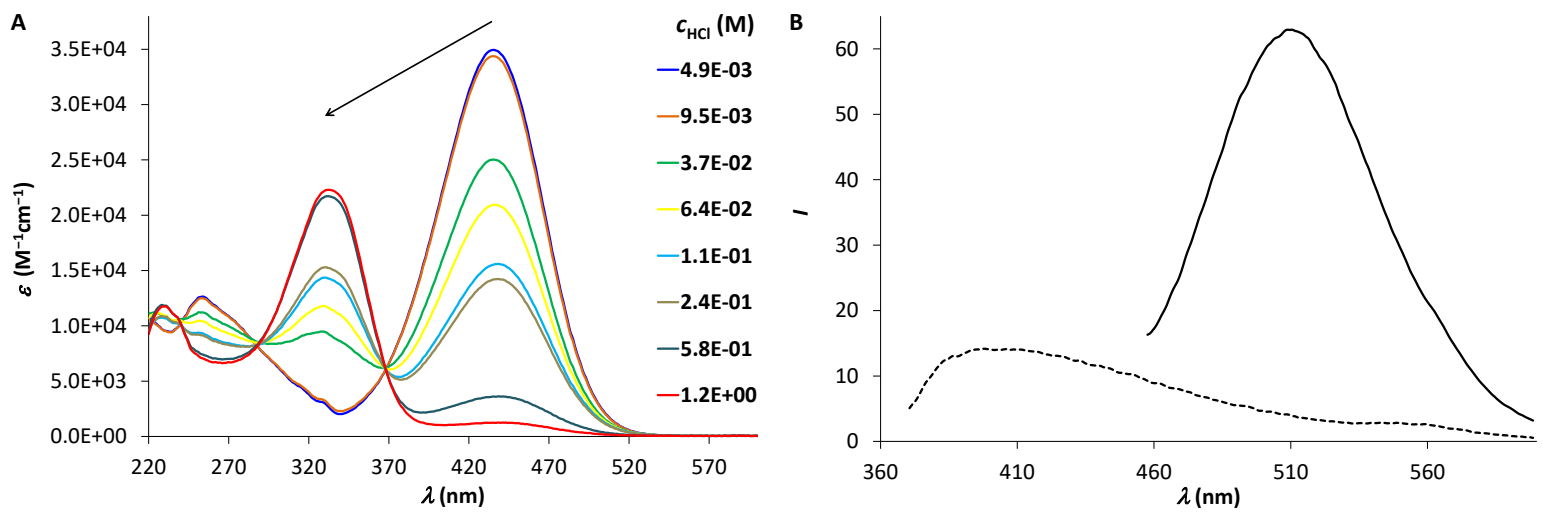

Figure 4. A: Change of the absorption spectra of $1 \mathrm{f}$ when titrated with $\mathrm{HCl}(0.01 \mathrm{M})$. B: Change of the emission spectra of 1 if in $\mathrm{CH}_{3} \mathrm{OH}$ (continuous line, $\lambda_{e x}=435 \mathrm{~nm}$ ) and in $\mathrm{CH}_{3} \mathrm{OH}$ containing $\mathrm{HCl}(1.2 \mathrm{M})$ (dashed line, $\left.\lambda_{\mathrm{ex}}=330 \mathrm{~nm}\right)$. The arrow indicates the direction of change. 

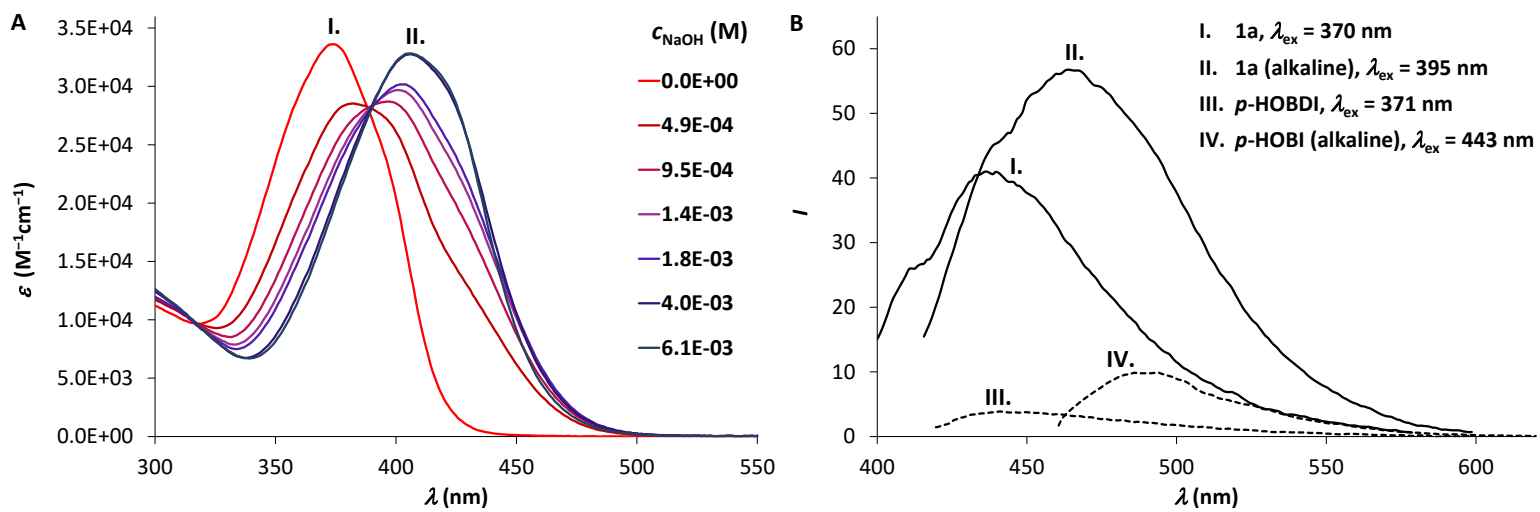

Figure 5. A: Change of the absorption spectra of 1a during titration with $\mathrm{NaOH}$. B: Change of the emission spectra of 1a (continuous lines), compared to the spectra recorded for the reference compound $p$-HOBDI (dashed lines).

\section{Solvent effects}

The solvent dependence of the absorption (Figure 6A) and emission spectra (Figure 6B) of 1a and 1g were investigated and analyzed in five different solvents, such as the protic $\mathrm{MeOH}$, the aprotic DCM, THF, MeCN and DMSO. The absorption spectra of both $1 \mathrm{a}$ and $\mathbf{1 g}$ showed only poor solvent dependence in terms of the wavelengths of the absorption maxima as well as their intensities, since only slight differences could be observed. In contrast with the absorption spectra, strong solvent dependence could be observed for the emission spectra of $\mathbf{1 a}$ and $\mathbf{1 g}$. The wavelength of the emission intensity maximum of the spectra of $\mathbf{1 a}$ in the different solvents is unchanged, while the intensities proved to be larger in aprotic solvents, than in the protic $\mathrm{MeOH}$. Besides, the hydrogen bond acceptor (HBA) solvent DMSO also stabilizes the S1-state. This can be attributed to the strong hydrogen bonding effect of DMSO, which stabilizes the more ionic resonance structure of 1a.

Compound $1 \mathrm{~g}$ exhibits the highest wavelength of the emission intensity maximum in the protic $\mathrm{MeOH}$ solvent with respect to other, aprotic solvents. The largest intensity was observed in DMSO, which indicates that high relative permittivity can stabilize the S1 state most efficiently.
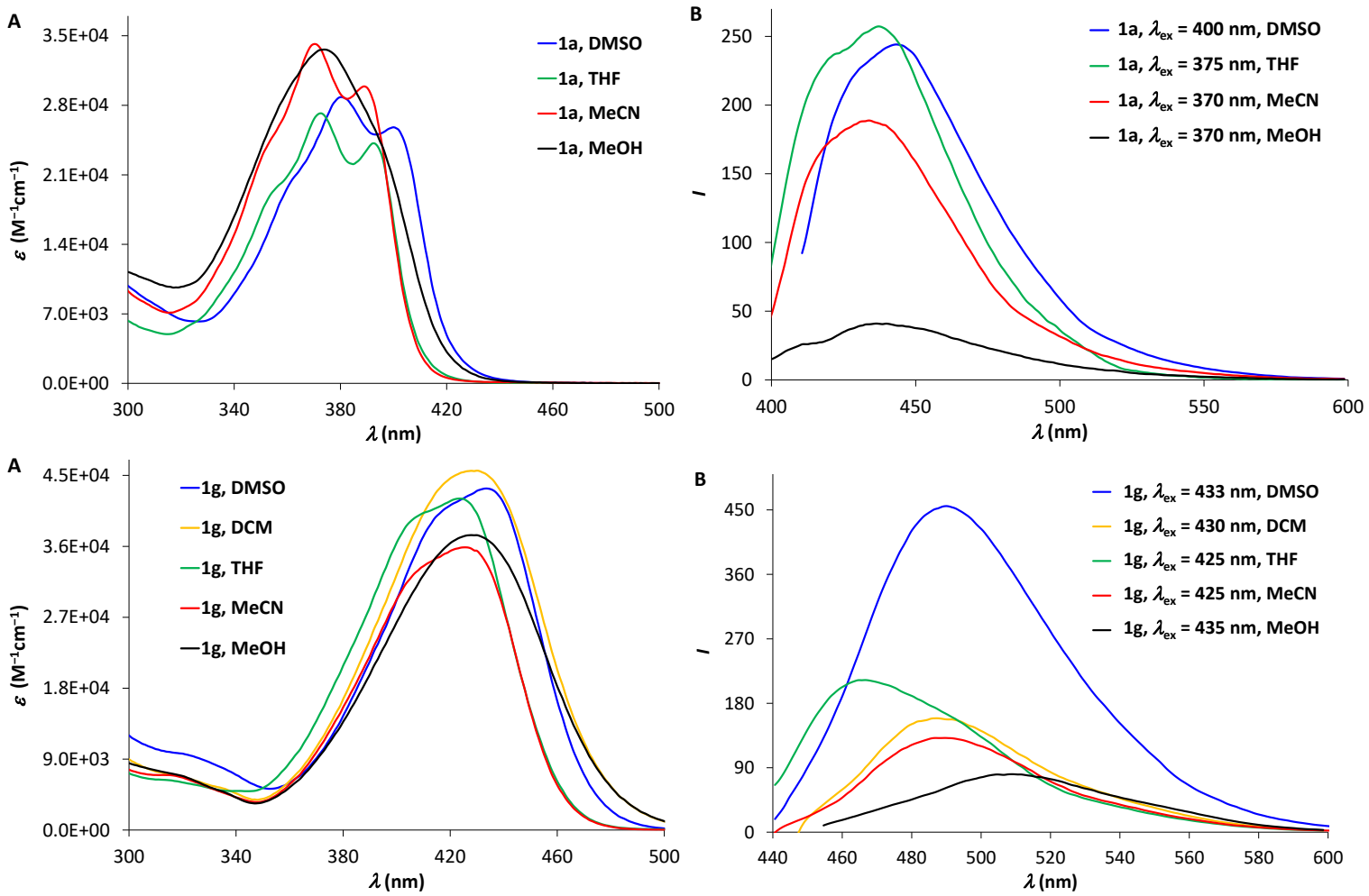

Figure 6. Absorption (A) and fluorescence emission (B) spectra of 1a (upper panel) as well as $\mathbf{1 g}$ (bottom panel) recorded in various solvents $(\mathrm{DMSO}=$ dimethyl sulfoxide, $\mathrm{DCM}=$ dichloromethane, $\mathrm{THF}=$ tetrahydrofuran, $\mathrm{MeCN}=$ acetonitrile, and $\mathrm{MeOH}=\mathrm{methanol}$ ), respectively. 


\section{Conclusion}

In this work, sixteen new GFP analogue fluorophores were synthesized and their absorption and fluorescence spectroscopy features described. In addition to this, further three analogues (compounds $\mathbf{1 e}, \mathbf{1 i}$ and $\mathbf{1 j}$ ) were also characterized spectroscopically for the first time. Our synthetic investigations revealed that the replacement of the 2-Me group with a phenyl substituted amino group of the imidazolone ring in $p$-HOBDI substantially increased the emission intensity (the increase is 8 to 32 -fold depending on the quality of the substituents of the phenyl ring of the scaffold). At the same time, the largest Stokes shift $\left(\lambda_{\mathrm{em}}-\lambda_{\mathrm{ex}}=144 \mathrm{~nm}\right)$ was observed when the substitution on the phenyl ring of $p$-HOBDI was changed from 4-OH to $4-\mathrm{NO}_{2}$, which increased the absorption (excitation) and emission maxima to $414 \mathrm{~nm}$ and 558 $\mathrm{nm}$, respectively, accompanied by a moderately increased emission intensity. The highest analytical spectroscopy potential is presented by compound $\mathbf{1 g}\left(4-\mathrm{Et}_{2} \mathrm{~N}\right.$ group), which not only shows a strong emission, but there is no significant overlap between the absorption and emission bands and this facilitates selective excitation and detection in applications. We attribute the observed large fluorescent intensities of the compounds to the enhanced ICT mechanism. The effect of $\mathrm{pH}$ and solvent (MeOH, DCM, THF, MeCN and DMSO) on the spectroscopy features of selected compounds was also studied.

The present work is also the first in the literature that provides a comparison between spectroscopy data and (para) Hammett constants of substituent groups of the synthesized fluorophores. Clear correlations with the EDG/EWD character of the substituent groups in the 4-monosubstituted derivatives and the spectroscopy features of the compounds were found. Results from aromaticity calculations are also presented and these were found to support the ICT hypothesis.

\section{Acknowledgements}

This project was supported by National Research, Development and Innovation Fund of Hungary, financed under the [KFI_16-1-20160177; NVKP_16-1-2016-0043; OTKA PD 128612] funding scheme.

\section{Appendix A}

Appendix contains the NMR, UV and fluorescence spectra of the compounds studied. It also describes the concept of aromaticity calculation and detailed Computational Methods. Table S2-S6 contains the computed raw energies, $(E)$, zero-point energies $\left(E_{2 \mathrm{PE}}\right)$, internal energies $(U)$, enthalpies $(H)$, Gibbs free energies $(G)$ and entropies $(S)$ in hartree $(\mathrm{Ha})$ at B3LYP/6-31G $(\mathrm{d}, \mathrm{p})$ level of theory.

Keywords: ICT • fluorescence • GFP • aromaticity • Hammet constant

\section{References}

1. Prendergast, F. G.; Mann, K. G. Chemical and physical properties of aequorin and the green fluorescent protein isolated from Aequorea forskalea. Biochemistry 1978, 17, 3448-3453, doi:10.1021/bi00610a004.

2. Tsien, R. The Green Fluorescent Protein. Annu. Rev. Biochem. 1998, 67, 509-544, doi:10.1146/annurev.biochem.67.1.509.

3. Scott, D. J.; Gunn, N. J.; Yong, K. J.; Wimmer, V. C.; Veldhuis, N. A.; Challis, L. M.; Haidar, M.; Petrou, S.; Bathgate, R. A. D.; Griffin, M. D. W. A Novel Ultra-Stable, Monomeric Green Fluorescent Protein for Direct Volumetric Imaging of Whole Organs Using CLARITY. Sci. Rep. 2018, 8, 1-15, doi:10.1038/s41598-017-18045-y.

4. Phillips, G. J. Green fluorescent protein - a bright idea for the study of bacterial protein localization. Fems Microbiol. Lett. 2001, 204, 918.

5. Lakadamyali, M.; Rust, M. J.; Babcock, H. P.; Zhuang, X. Visualizing infection of individual influenza viruses. Proc. Natl. Acad. Sci. 2003, 100, 9280-9285, doi:10.1073/pnas.0832269100.

6. Remy, S.; Tesson, L.; Usal, C.; Menoret, S.; Bonnamain, V.; Nerriere-Daguin, V.; Rossignol, J.; Boyer, C.; Nguyen, T. H.; Naveilhan, P.; Lescaudron, L.; Anegon, I. New lines of GFP transgenic rats relevant for regenerative medicine and gene therapy. Transgenic Res. 2010, 19, 745-763, doi:10.1007/s11248-009-9352-2.

7. Fakhrudin, N.; Ladurner, A.; Atanasov, A. G.; Heiss, E. H.; Baumgartner, L.; Markt, P.; Schuster, D.; Ellmerer, E. P.; Wolber, G.; Rollinger, J. M.; Stuppner, H.; Dirsch, V. M. Computer-aided discovery, validation, and mechanistic characterization of novel neolignan activators of peroxisome proliferator-activated receptor gamma. Mol. Pharmacol. 2010, 77, 559-66, doi:10.1124/mol.109.062141. 

2000, 40, 360-369, doi:10.1006/cryo.2000.2258.

9. Yang, F.; Moss, L. G.; Phillips, G. N.; Phillips Jr., G. N.; Phillips, G. N. The molecular structure of green fluorescent protein. Nat. Biotechnol. 1996, 14, 1246-1251, doi:10.1038/nbt1096-1246.

10. Zimmer, M. Green fluorescent protein (GFP): Applications, structure, and related photophysical behavior. Chem. Rev. 2002, 102, 759781, doi:10.1021/cr010142r.

11. Barondeau, D. P.; Kassmann, C. J.; Tainer, J. A.; Getzoff, E. D. Understanding GFP chromophore biosynthesis: Controlling backbone cyclization and modifying post-translational chemistry. Biochemistry 2005, 44, 1960-1970, doi:10.1021/bi0479205.

Barondeau, D. P.; Putnam, C. D.; Kassmann, C. J.; Tainer, J. A.; Getzoff, E. D. Mechanism and energetics of green fluorescent protein chromophore synthesis revealed by trapped intermediate structures. Proc. Natl. Acad. Sci. 2003, 100, 12111-12116, doi:10.1073/pnas.2133463100.

Ivashkin, P. E.; Lukyanov, K. A.; Lukyanov, S.; Yampolsky, I. V. A synthetic GFP-like chromophore undergoes base-catalyzed autoxidation into acylimine red form. J. Org. Chem. 2011, 76, 2782-2791, doi:10.1021/jo200150b.

Pakhomov, A. A.; Martynov, V. I. GFP Family: Structural Insights into Spectral Tuning. Chem. Biol. 2008, 15, 755-764, doi:10.1016/j.chembiol.2008.07.009.

Nienhaus, K.; Nienhaus, G. U.; Wiedenmann, J.; Nar, H. Structural basis for photo-induced protein cleavage and green-to-red conversion of fluorescent protein EosFP. Proc. Natl. Acad. Sci. U. S. A. 2005, 102, 9156-9, doi:10.1073/pnas.0501874102. Lukyanov, S. A. GFP-like chromoproteins as a source of far-red fluorescent proteins. FEBS Lett. 2001, 507, 16-20, doi:10.1016/S00145793(01)02930-1.

Kilgard, R.; Heim, A. B.; Tsien, R. Y. Improved green fluorescence. Nature 1995, 373, 663-664. Fluorescent Protein. Science (80-. ). 1996, 273, 1392-1395, doi:10.1126/science.273.5280.1392.

Matz, M. V.; Fradkov, A. F.; Labas, Y. A.; Savitsky, A. P.; Zaraisky, A. G.; Markelov, M. L.; Lukyanov, S. A. Fluorescent proteins from nonbioluminescent Anthozoa species. Nat. Biotechnol. 1999, 17, 969-973, doi:10.1038/13657.

Ai, H. W.; Shaner, N. C.; Cheng, Z.; Tsien, R. Y.; Campbell, R. E. Exploration of new chromophore structures leads to the identification of improved blue fluorescent proteins. Biochemistry 2007, 46, 5904-5910, doi:10.1021/bi700199g.

Brejc, K.; Sixma, T. K.; Kitts, P. A.; Kain, S. R.; Tsien, R. Y.; Ormo, M.; Remington, S. J. Structural basis for dual excitation and photoisomerization of the Aequorea victoria green fluorescent protein. Proc. Natl. Acad. Sci. 1997, 94, 2306-2311, doi:10.1073/pnas.94.6.2306.

Piatkevich, K. D.; Malashkevich, V. N.; Almo, S. C.; Verkhusha, V. V. Engineering ESPT pathways based on structural analysis of LSSmKate red fluorescent proteins with large stokes shift. J. Am. Chem. Soc. 2010, 132, 10762-10770, doi:10.1021/ja101974k.

Chattoraj, M.; King, B. A.; Bublitz, G. U.; Boxer, S. G. Ultra-fast excited state dynamics in green fluorescent protein: multiple states and proton transfer. Proc. Natl. Acad. Sci. USA 1996, 93, 8362-7, doi:10.1073/pnas.93.16.8362. fluorescent protein mKeima. J. Am. Chem. Soc. 2009, 131, 13212-3, doi:10.1021/ja904665x. increased photostability and pH insensitivity. Nat. Methods 2009, 6, 351-353, doi:10.1038/nmeth.1317. Acad. Sci. 1994, 91, 12501-12504, doi:10.1073/pnas.91.26.12501. 
Soc. 2012, 134, 6025-6032, doi:10.1021/ja3010144.

Mandal, D.; Tahara, T.; Meech, S. R. Excited-State Dynamics in the Green Fluorescent Protein Chromophore. 2004, 1102-1108.

Yuan, L.; Lin, W.; Chen, H.; Zhu, S.; He, L. A unique family of rigid analogues of the GFP chromophore with tunable two-photon action cross-sections for biological imaging. Angew. Chemie - Int. Ed. 2013, 52, 10018-10022, doi:10.1002/anie.201303179.

Karolak-Wojciechowska, J.; Mrozek, A.; Kieć-Kononowicz, K.; Handzlik, J. Structure and activity studies of glycine receptor ligands. Part 8. Arylidene-imidazoline-4-one aminoacids. J. Mol. Struct. 2003, 649, 25-36, doi:10.1016/S0022-2860(02)00568-9.

Ermoli, A.; Bargiotti, A.; Brasca, M. G.; Ciavolella, A.; Colombo, N.; Fachin, G.; Isacchi, A.; Menichincheri, M.; Molinari, A.; Montagnoli, A.; Pillan, A.; Rainoldi, S.; Sirtori, F. R.; Sola, F.; Thieffine, S.; Tibolla, M.; Valsasina, B.; Volpi, D.; Santocanale, C.; Vanotti, E. Cell division cycle 7 kinase inhibitors: $1 \mathrm{H}$-pyrrolo[2,3-b]pyridines, synthesis and structure-activity relationships. J. Med. Chem. 2009, 52, 4380-4390, doi:10.1021/jm900248g.

Lakowicz Joseph R. Effects of Solvents on Fluorescence Emission Spectra. In Principles of Fluorescence Spectroscopy; Springer: Boston, 2006; pp. 187-215 ISBN 978-1-4615-7660-0.

Frisch, M. J.; Trucks, G. W.; Schlegel, H. B.; Scuseria, G. E.; Robb, M. A.; Cheeseman, J. R.; Scalmani, G.; Barone, V.; Mennucci, B.; Petersson, G. A.; Nakatsuji, H.; Caricato, M.; Li, X.; Hratchian, H. P.; Izmaylov, A. F.; Bloino, J.; Zheng, G.; Sonnenberg, J. L.; Hada, M.; Ehara, M.; Toyota, K.; Fukuda, R.; Hasegawa, J.; Ishida, M.; Nakajima, T.; Honda, Y.; Kitao, O.; Nakai, H.; Vreven, T.; Montgomery, J. A.; Peralta J. E.; Ogliaro, F.; Bearpark, M.; Heyd, J. J.; Brothers, E.; Kudin, K. N.; Staroverov, V. N.; Kobayashi, R.; Normand, J.; Raghavachari, K.; Rendell, A.; Burant, J. C.; Iyengar, S. S.; Tomasi, J.; Cossi, M.; Rega, N.; Millam, J. M.; Klene, M.; Knox, J. E.; Cross, J. B.; Bakken, V.; Adamo, C.; Jaramillo, J.; Gomperts, R.; Stratmann, R. E.; Yazyev, O.; Austin, A. J.; Cammi, R.; Pomelli, C.; Ochterski, J. W.; Martin, R. L.; Morokuma, K.; Zakrzewski, V. G.; Voth, G. A.; Salvador, P.; Dannenberg, J. J.; Dapprich, S.; Daniels, A. D.; Farkas, Ö.; Foresman, J. B.; Ortiz, J. V.; Cioslowski, J.; Fox, D. J. No Title. Gaussian, Inc., Wallingford CT 2009.

Becke, A. D. Density-functional thermochemistry. III. The role of exact exchange. J. Chem. Phys. 1993, 98, 5648-5652, doi:10.1063/1.464913.

Mucsi, Z.; Viskolcz, B.; Csizmadia, I. G. A quantitative scale for the degree of aromaticity and antiaromaticity: A comparison of theoretical and experimental enthalpies of hydrogenation. J. Phys. Chem. A 2007, 111, 1123-1132, doi:10.1021/jp0657686.

Kadry, A. M.; Mansour, S. A. Studies on 5-arylidene-3-phenyl-2-methylmercaptohydantoins. J. Heterocycl. Chem. 1985, 22, 155-157.

Daboun, H. A.; Ibrahim, Y. A. Rearrangement of 3-arylhydantoins into 3-aminoglycocyamidines. J. Heterocycl. Chem. $1982,19,41-43$.

Khodair, A. I.; Gesson, J.-P.; El-Sayed, H. E.-A. Synthesis of 15H-Triones and 14H-Trione as New Polycyclic Fused-Ring Systems. Phosphorus, Sulfur, Silicon Relat. Elem. 2004, 179, 2653-2665.

Zhu, H.; Wang, X.; Ma, R.; Kuang, Z.; Guo, Q.; Xia, A. Intramolecular Charge Transfer and Solvation of Photoactive Molecules with Conjugated Push-Pull Structures. ChemPhysChem 2016, 17, 3245-3251, doi:10.1002/cphc.201600674.

Hammett, L. P. The Effect of Structure upon the Reactions of Organic Compounds. Benzene Derivatives. J. Am. Chem. Soc. 1937, 59, 96-103, doi:10.1021/ja01280a022.

Mucsi, Z.; Csizmadia, I. G. Aromaticity and Antiaromaticity of Four-Membered P-Heterocycles. Curr. Org. Chem. 2008, 12, 83-96, doi:10.2174/138527208783330064.

Mucsi, Z.; Keglevich, G. Why are phosphole oxides unstable? The phenomenon of antiaromaticity as a destabilizing factor. European J. Org. Chem. 2007, 4765-4771, doi:10.1002/ejoc.200700293.

Mucsi, Z.; Szabó, A.; Hermecz, I.; Kucsman, Á.; Csizmadia, I. G. Modeling rate-controlling solvent effects. The pericyclic Meisenheimer rearrangement of N-propargylmorpholine N-oxide. J. Am. Chem. Soc. 2005, 127, 7615-7631, doi:10.1021/ja042227q. 
Protein

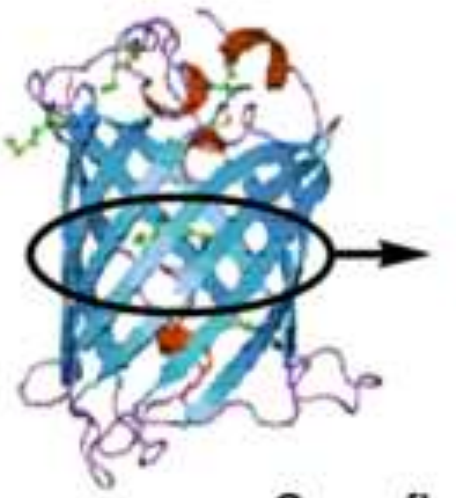

Green fluorescent protein (GFP)

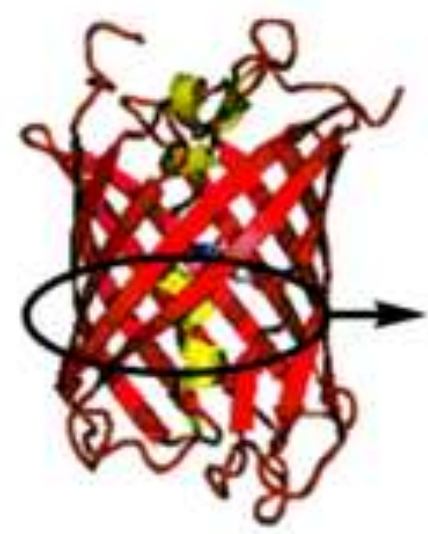

Red fluorescent protein (RFP)
Minimal

fluorescent scaffold

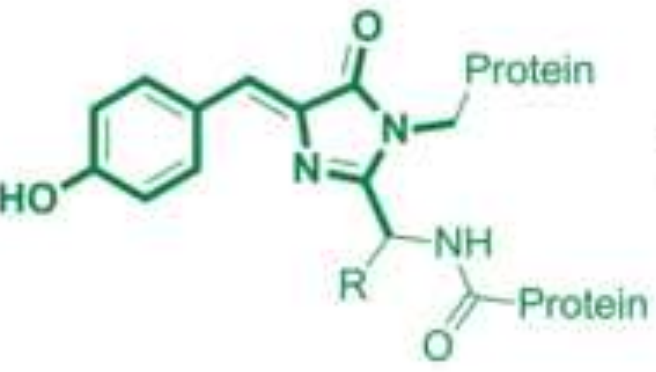

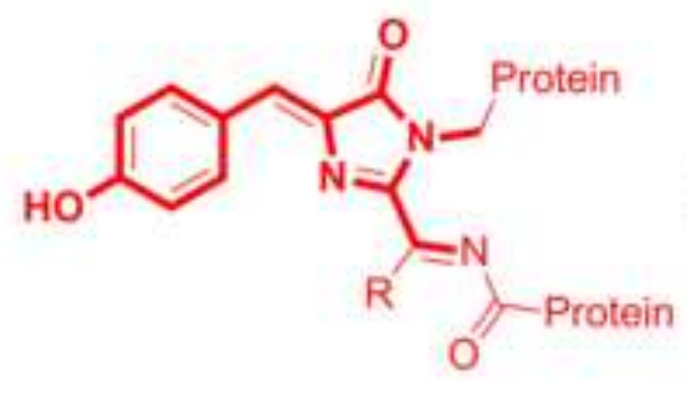

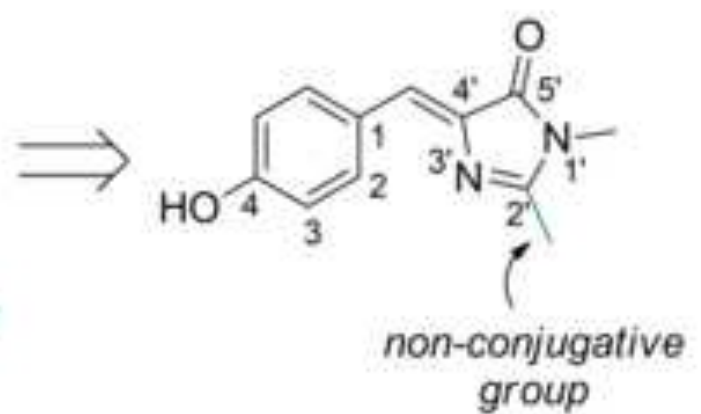

p-HOBDI (synthesized)

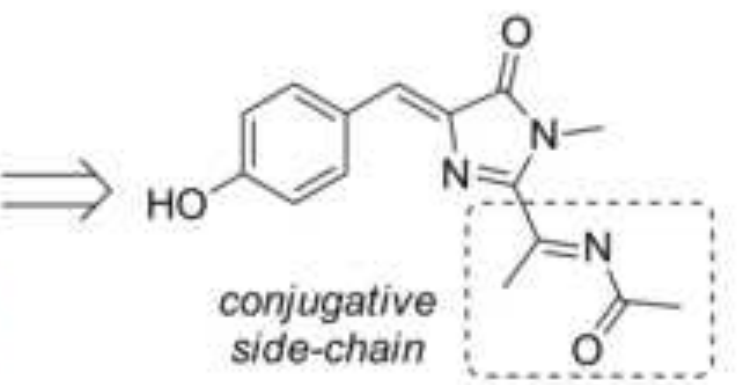

DsRed-like chromophore (HBMPDI, not synthesized)
New analogues

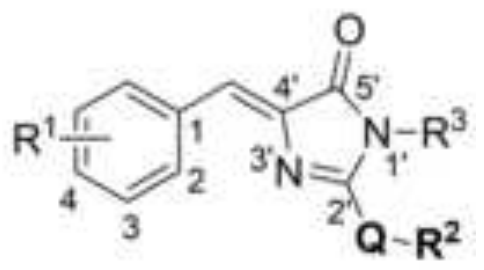

$$
\begin{aligned}
& R^{2}=\mathrm{Ph}, \mathrm{Bn} \\
& \mathrm{Q}=\mathrm{NH}, \mathrm{S} \\
& \mathrm{R}^{3}=\mathrm{H} \text { or } \mathrm{Me}
\end{aligned}
$$

1

Introduction of a new conjugative group 


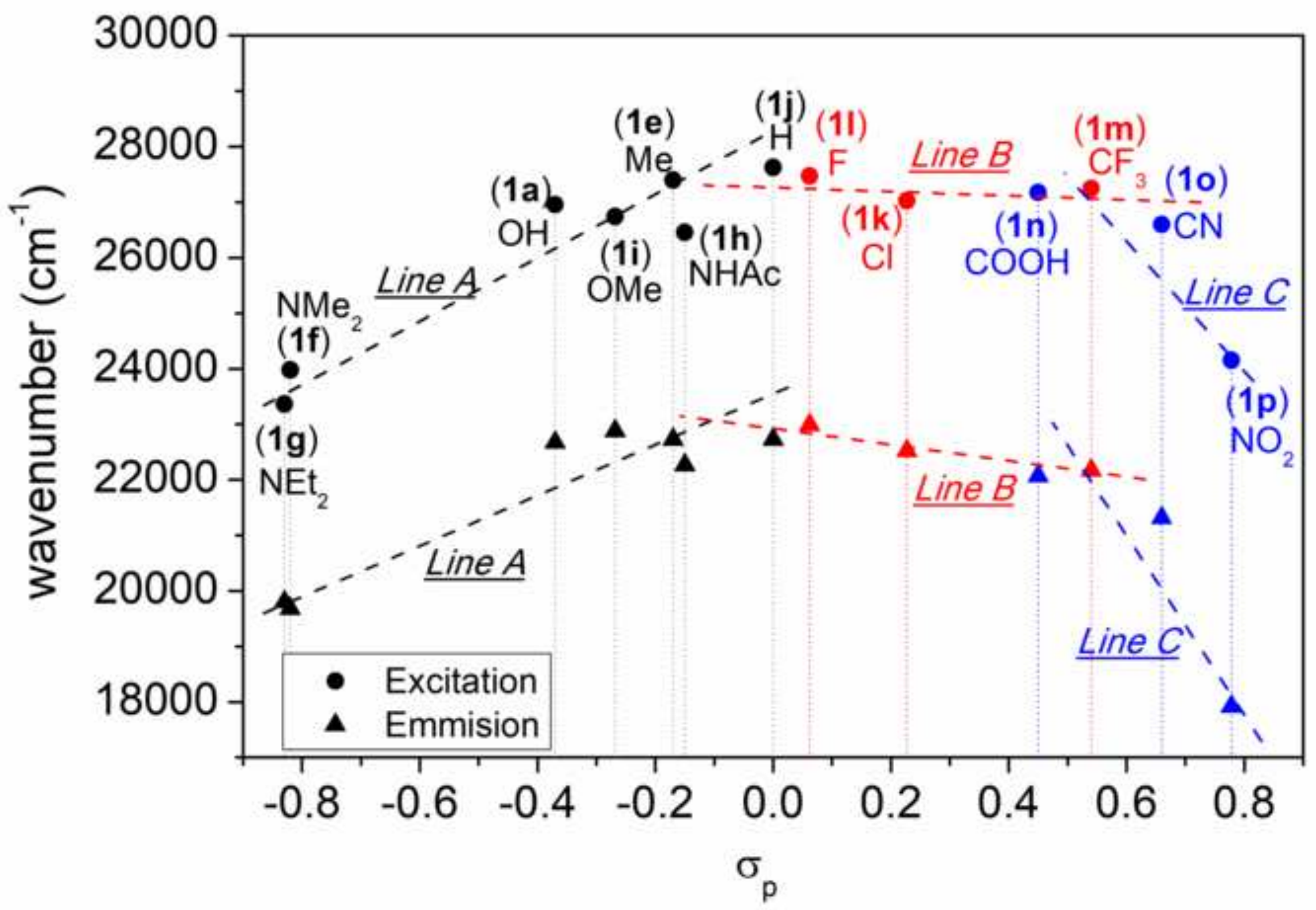




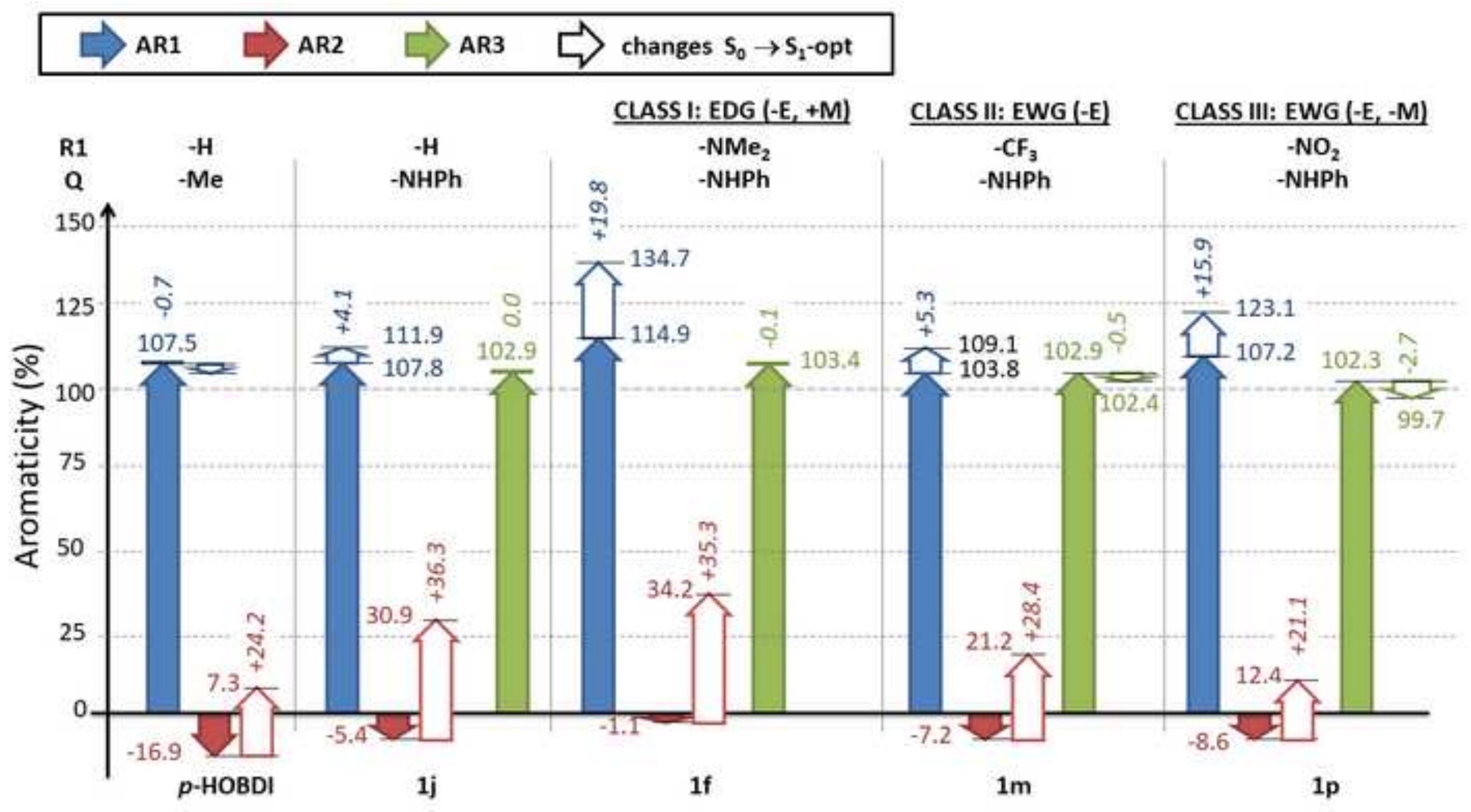




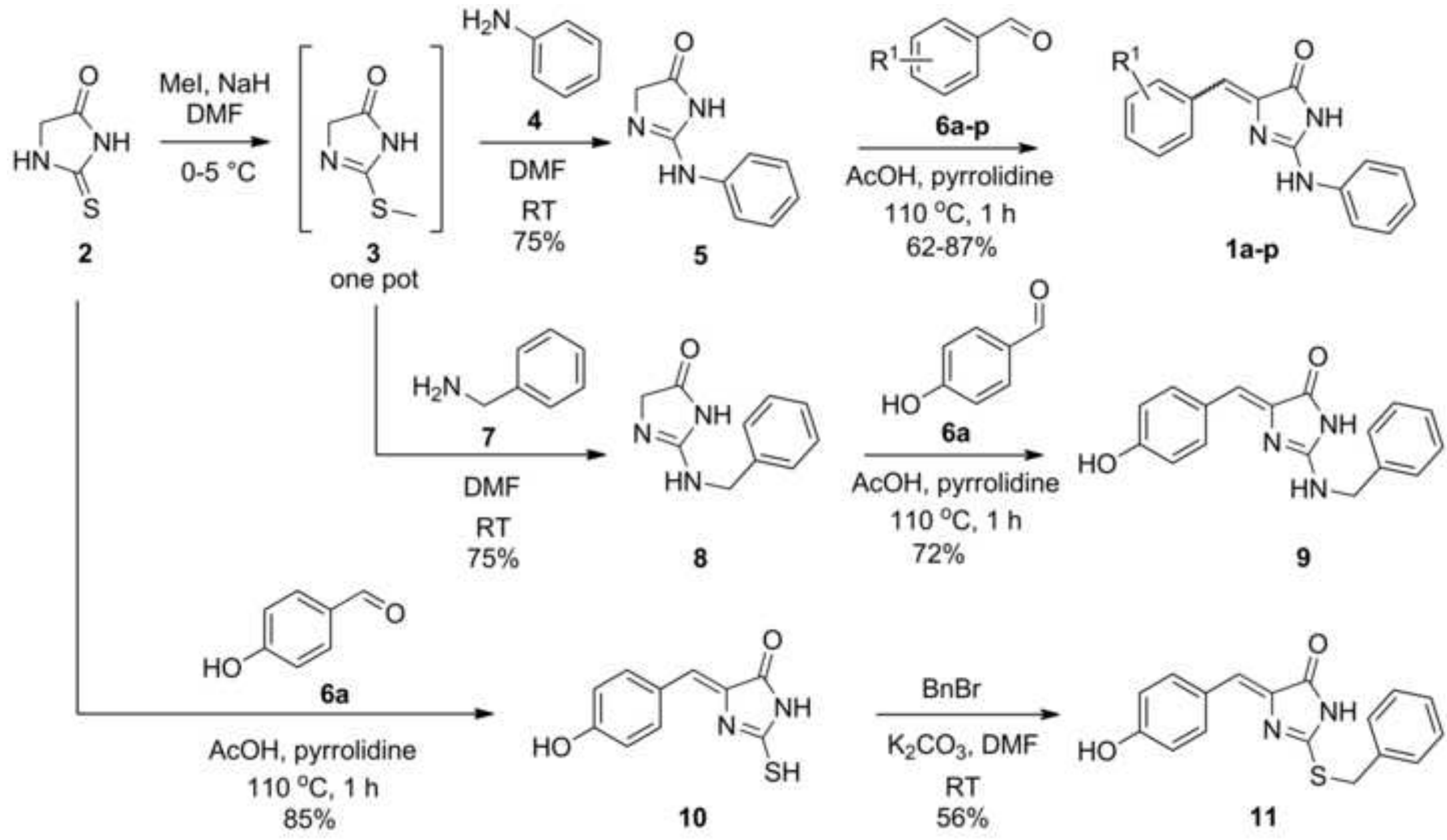




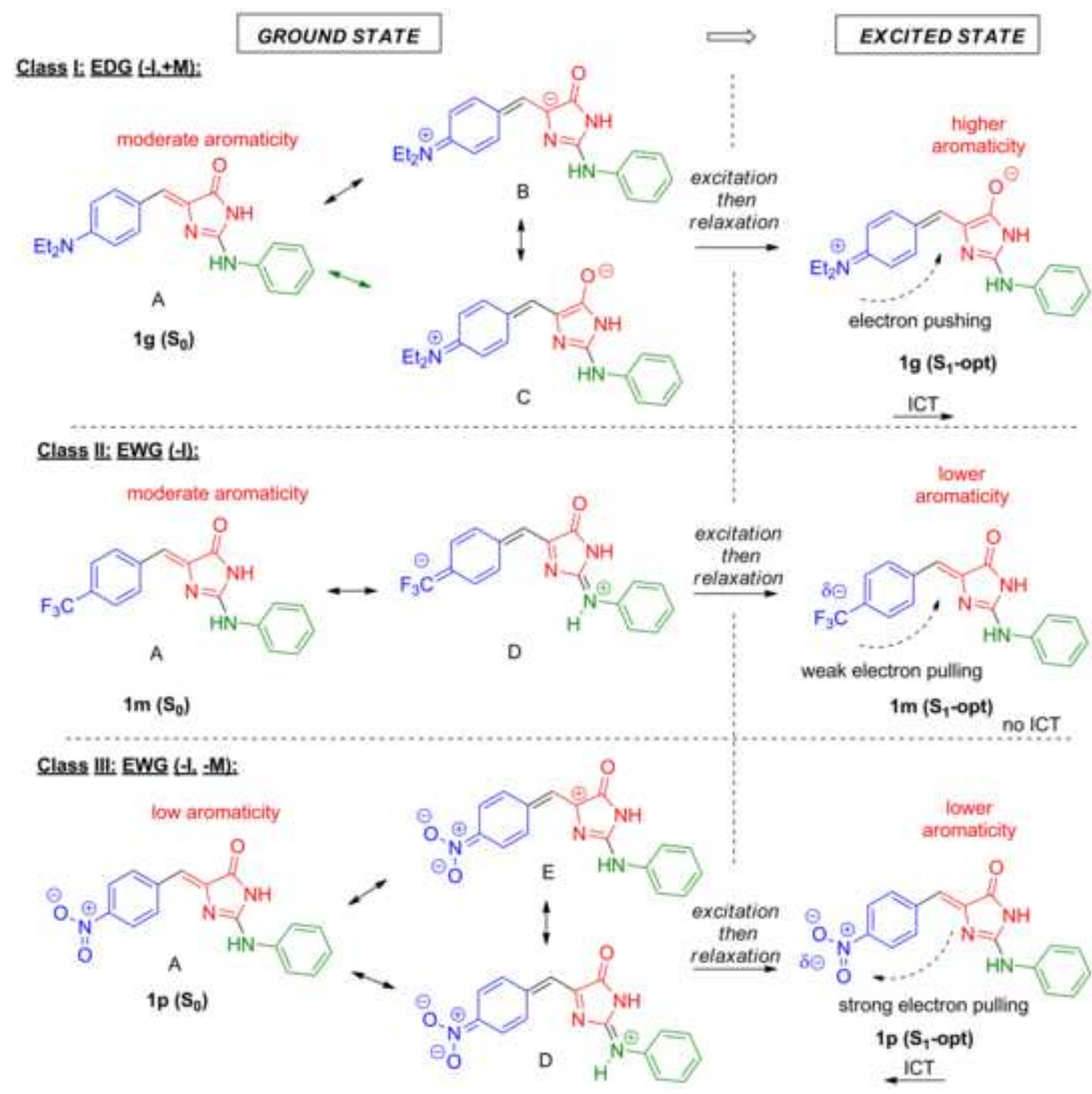




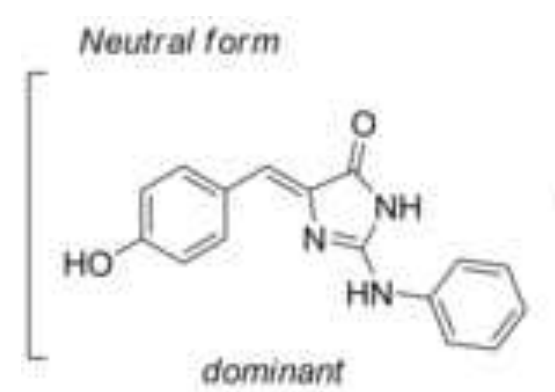

$1 a(A)$

\section{Deprotonated form}

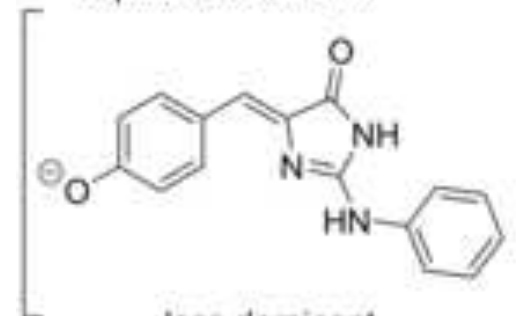

less dominant $\mathbf{1 a}-\mathrm{H}^{*}(\mathrm{~A})$

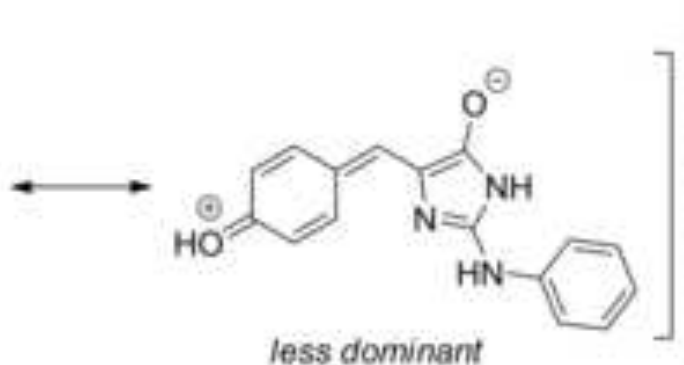

$1 \mathrm{a}(\mathrm{B})$
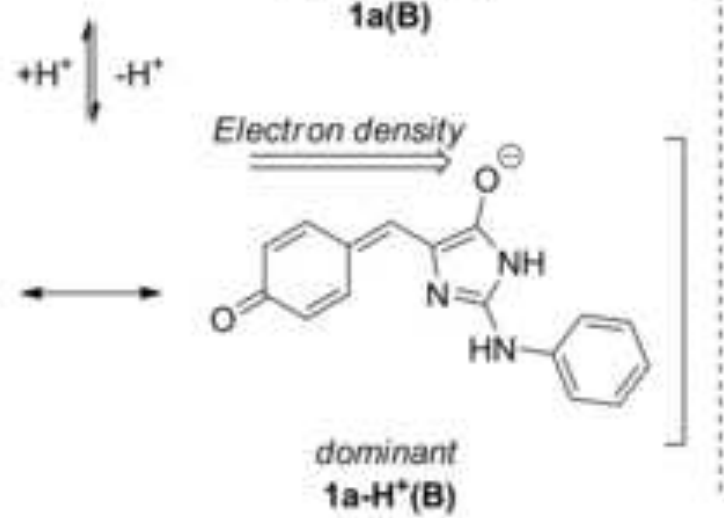

Neutral form

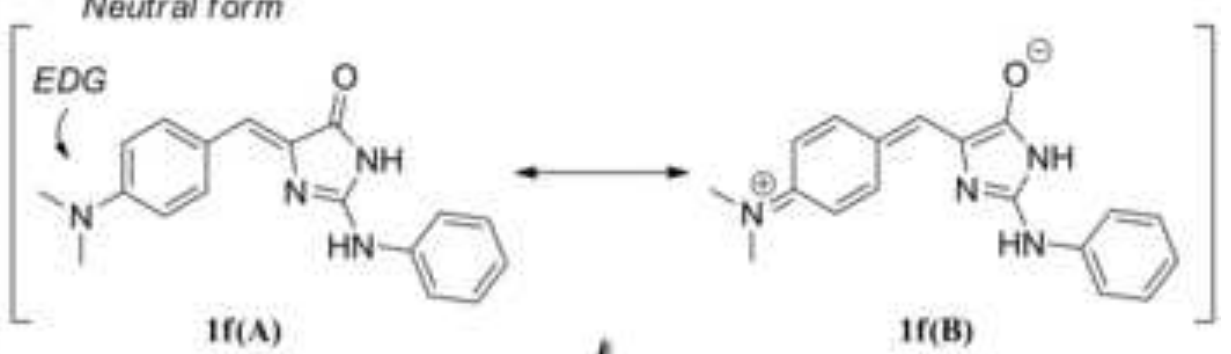

$$
-\mathrm{H}^{+},+\mathrm{H}^{*}
$$

Protonated form

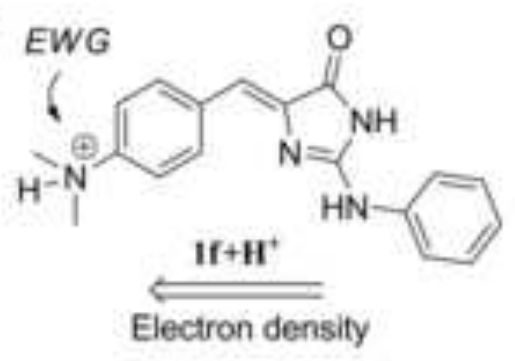




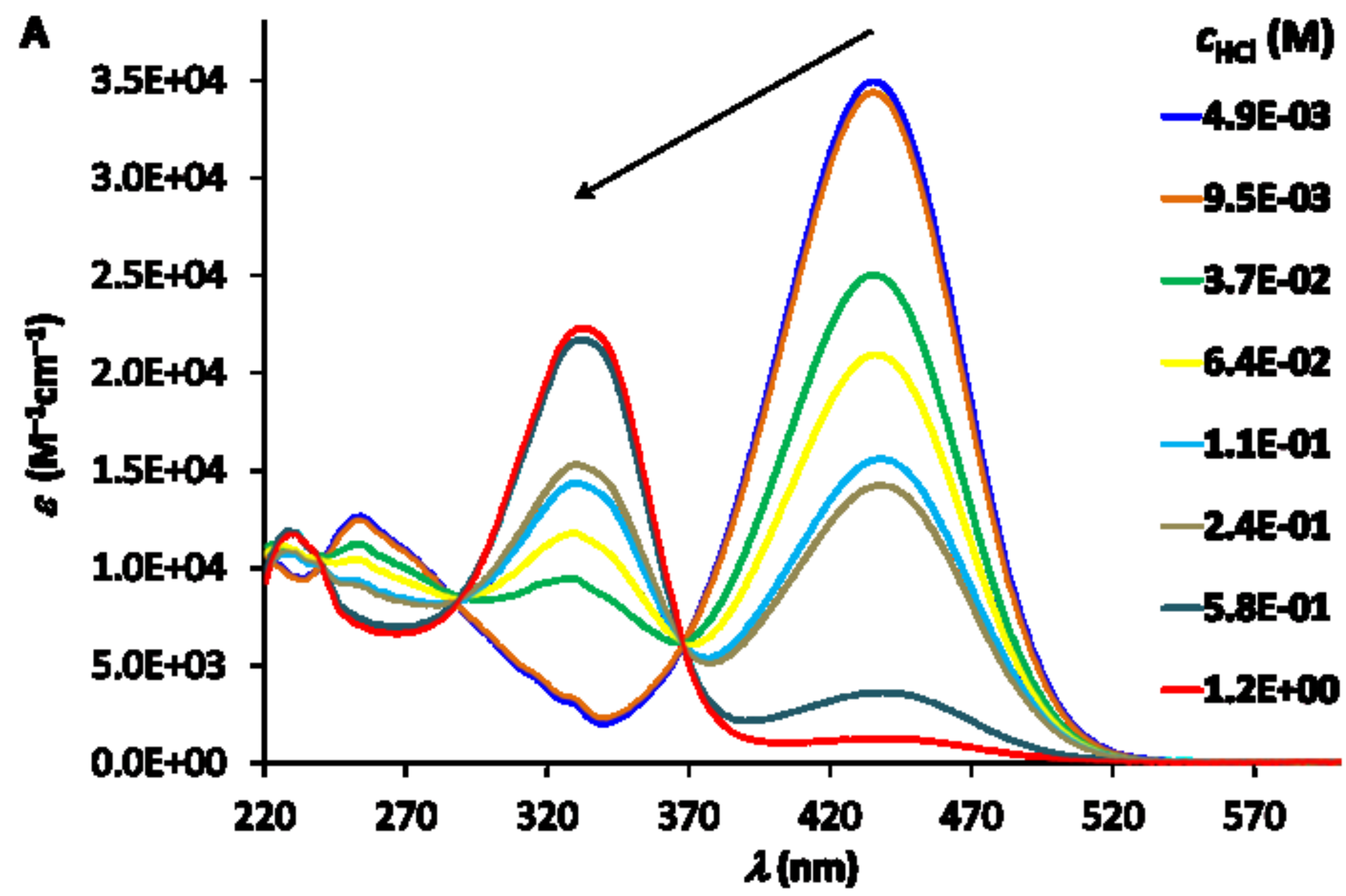




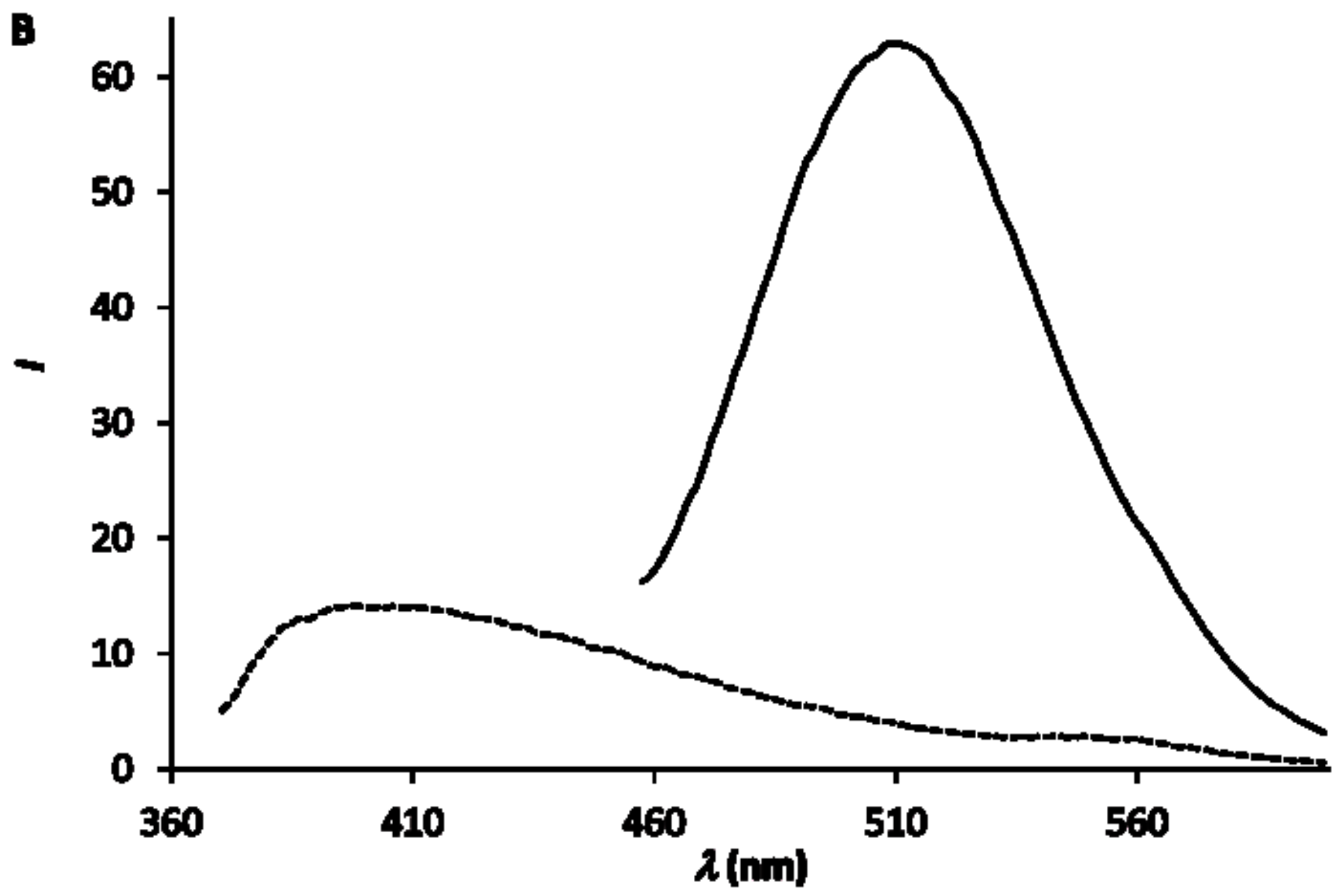




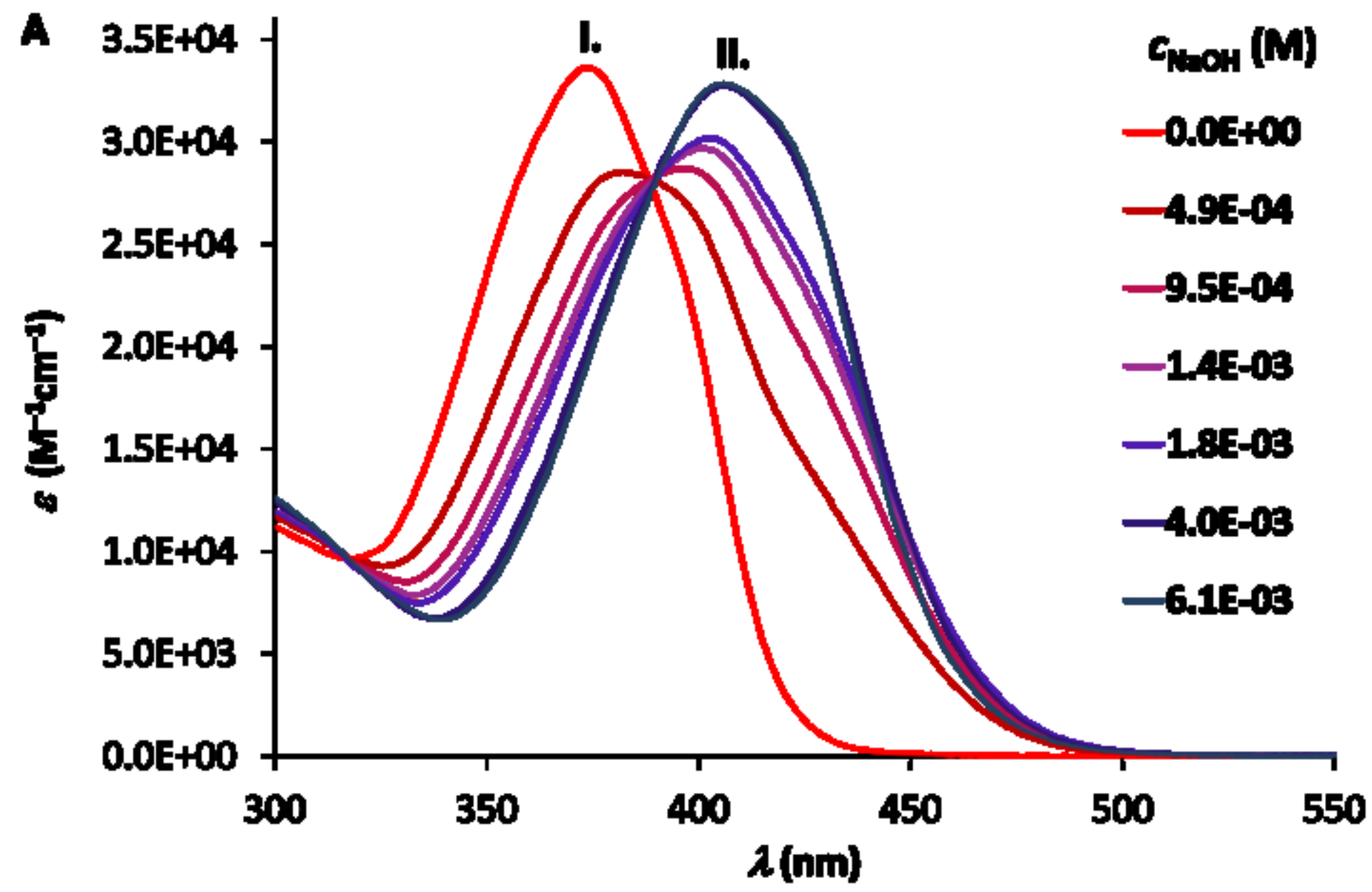




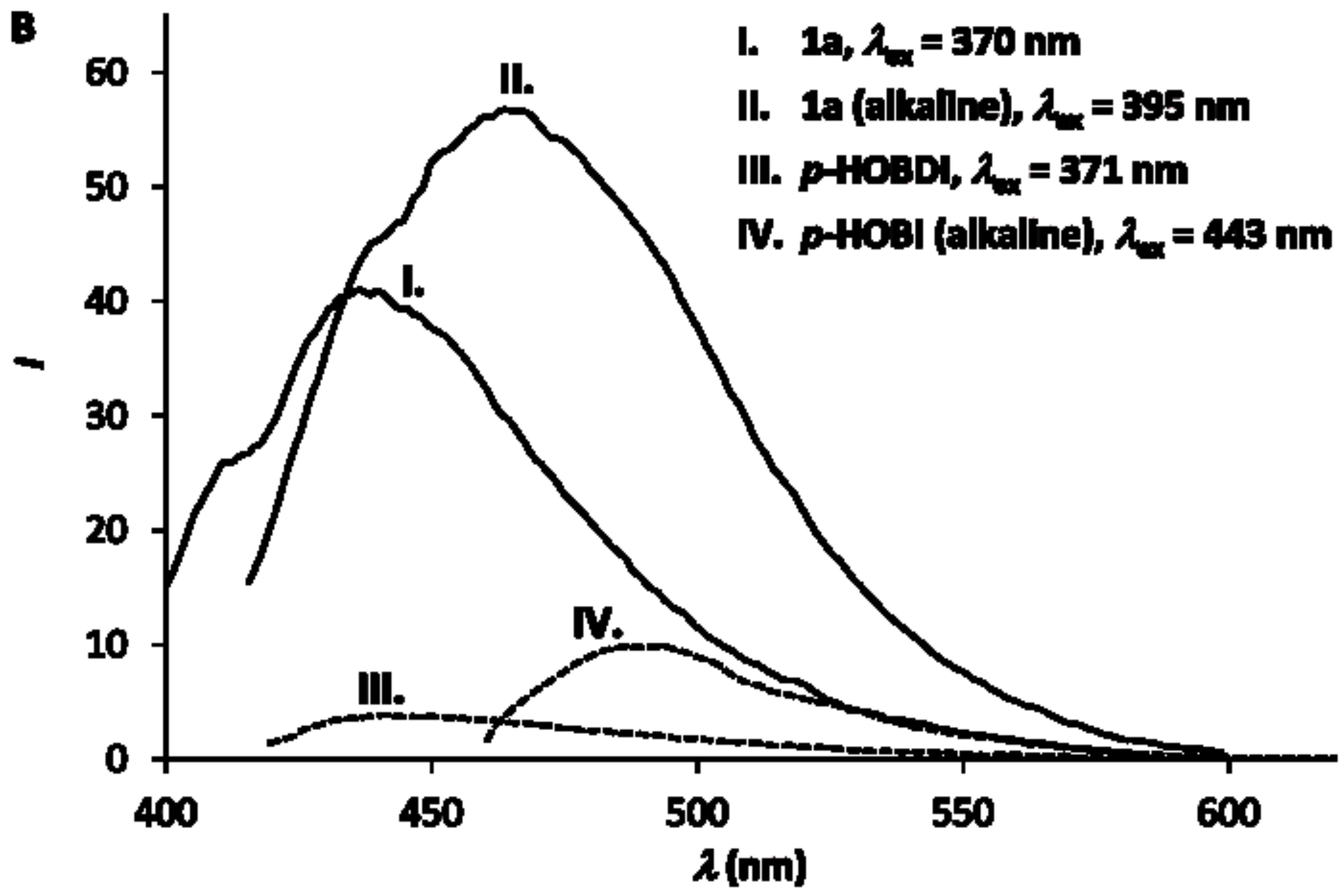




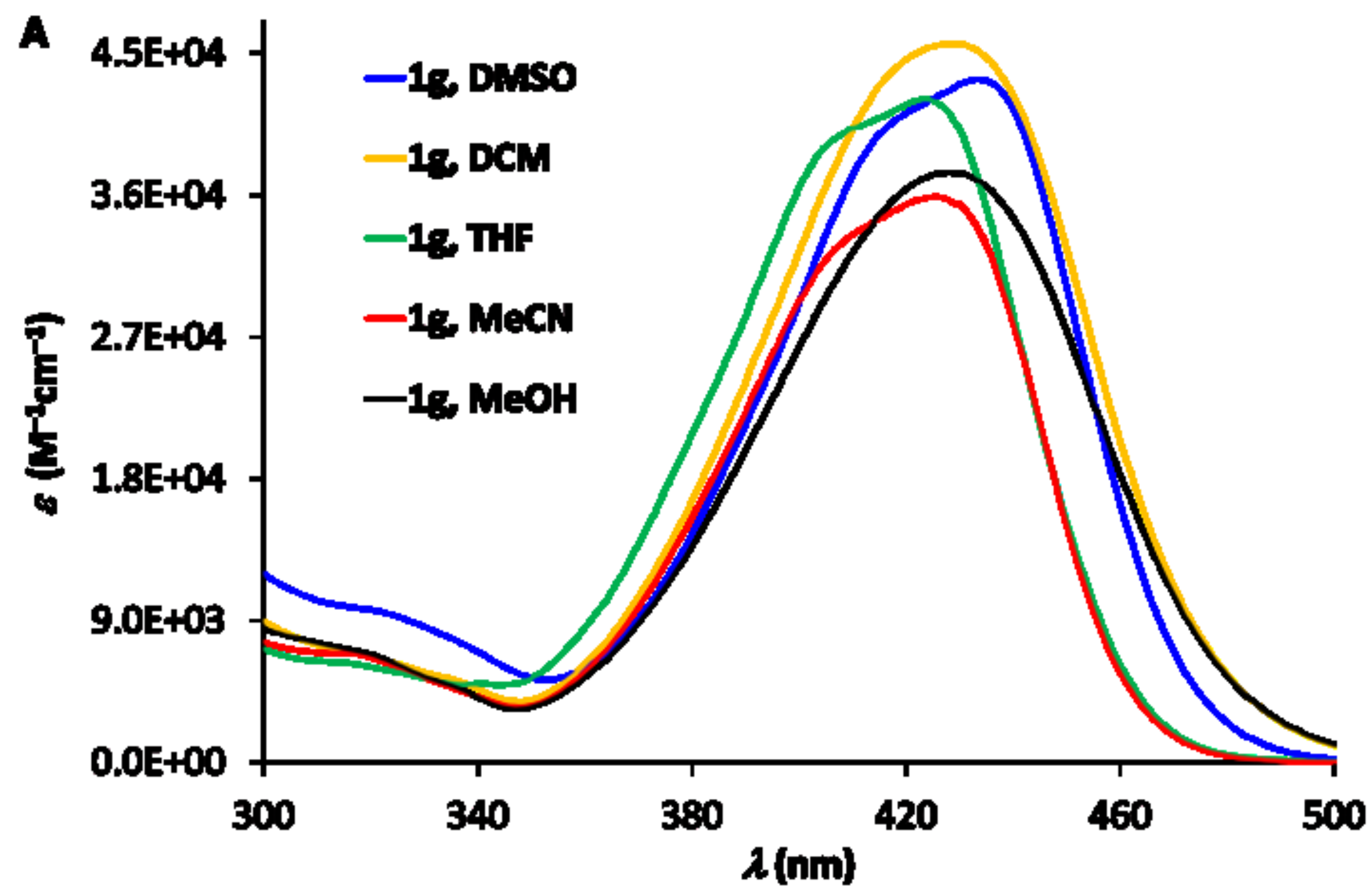




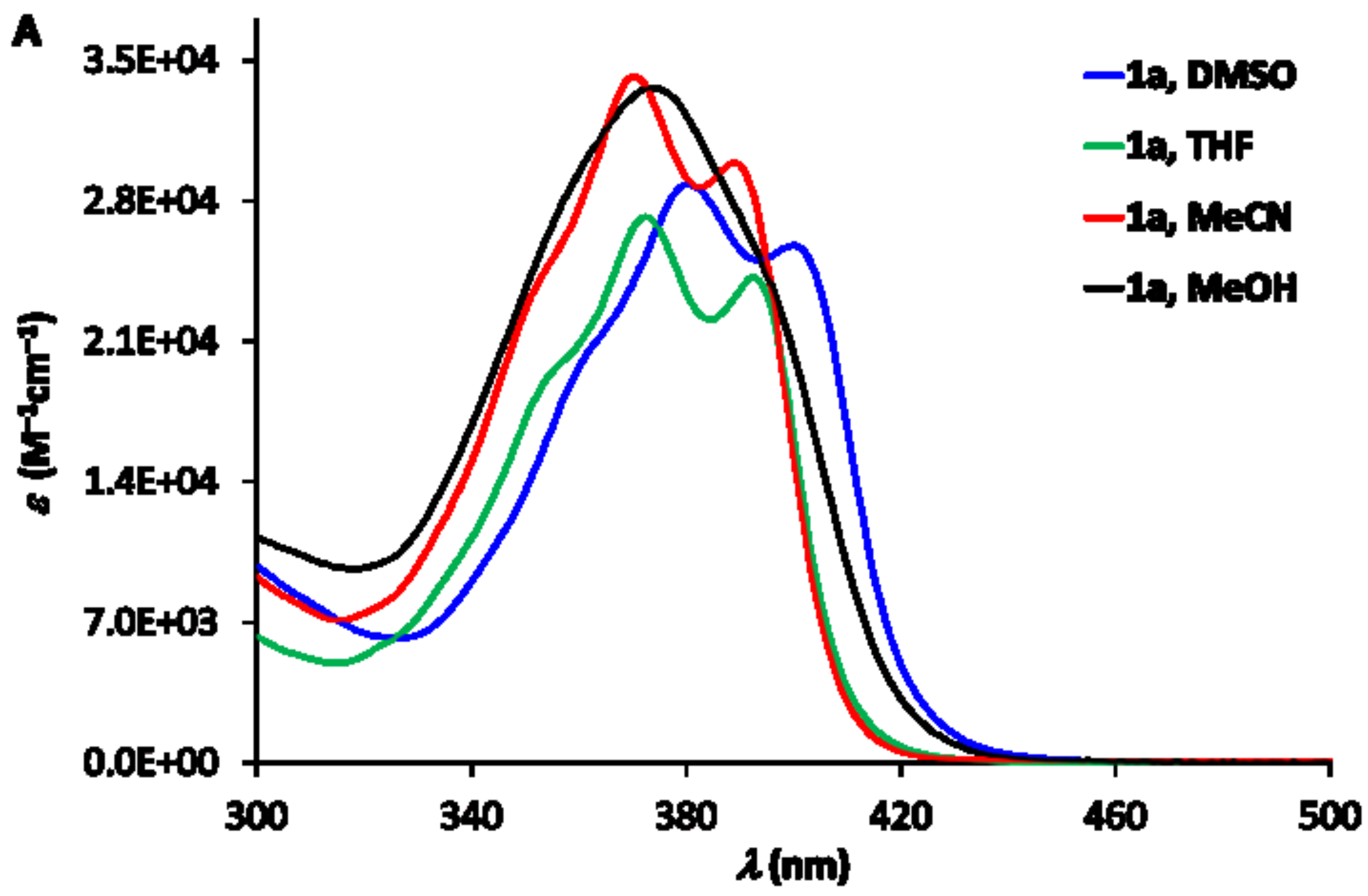




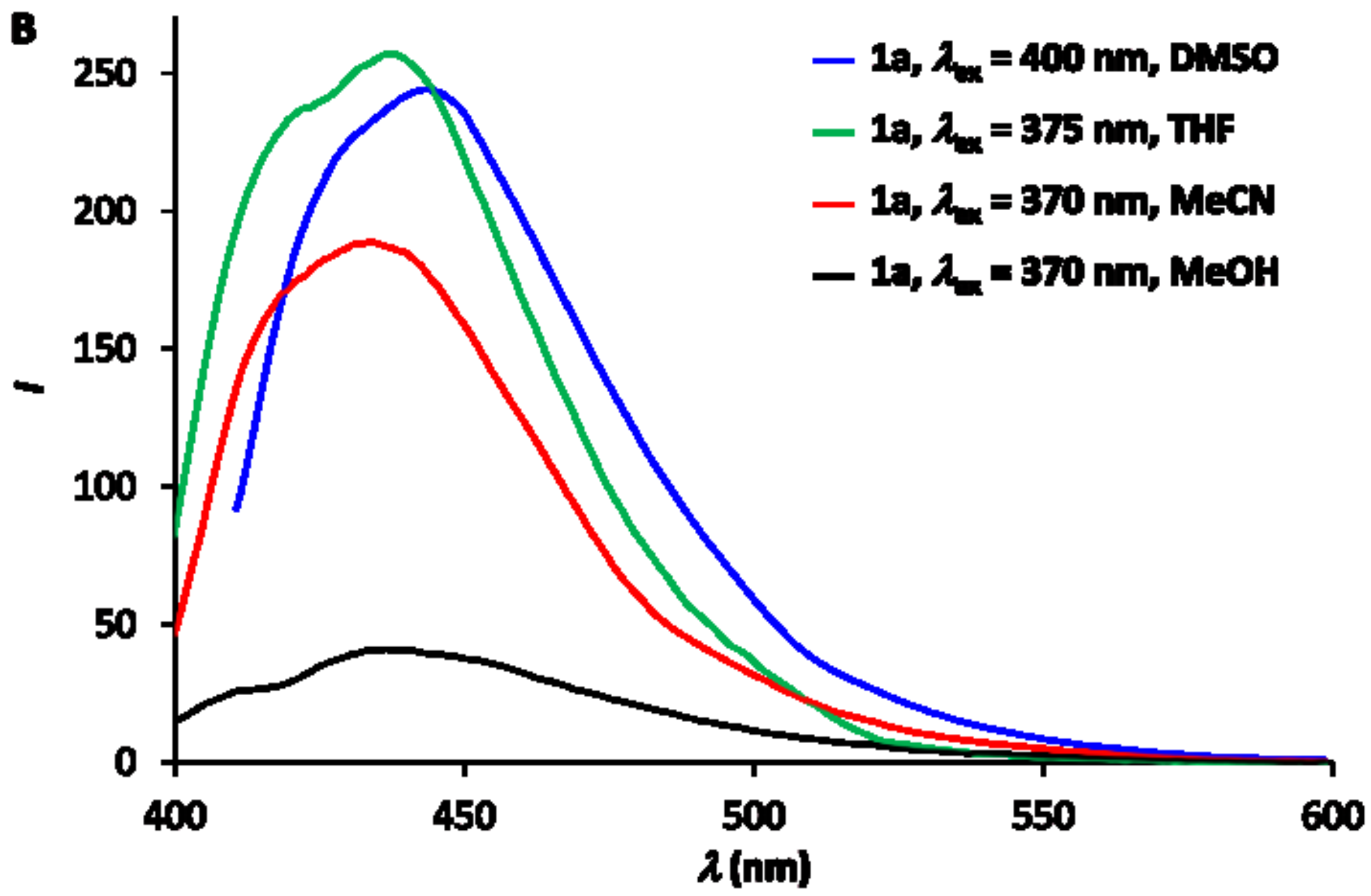




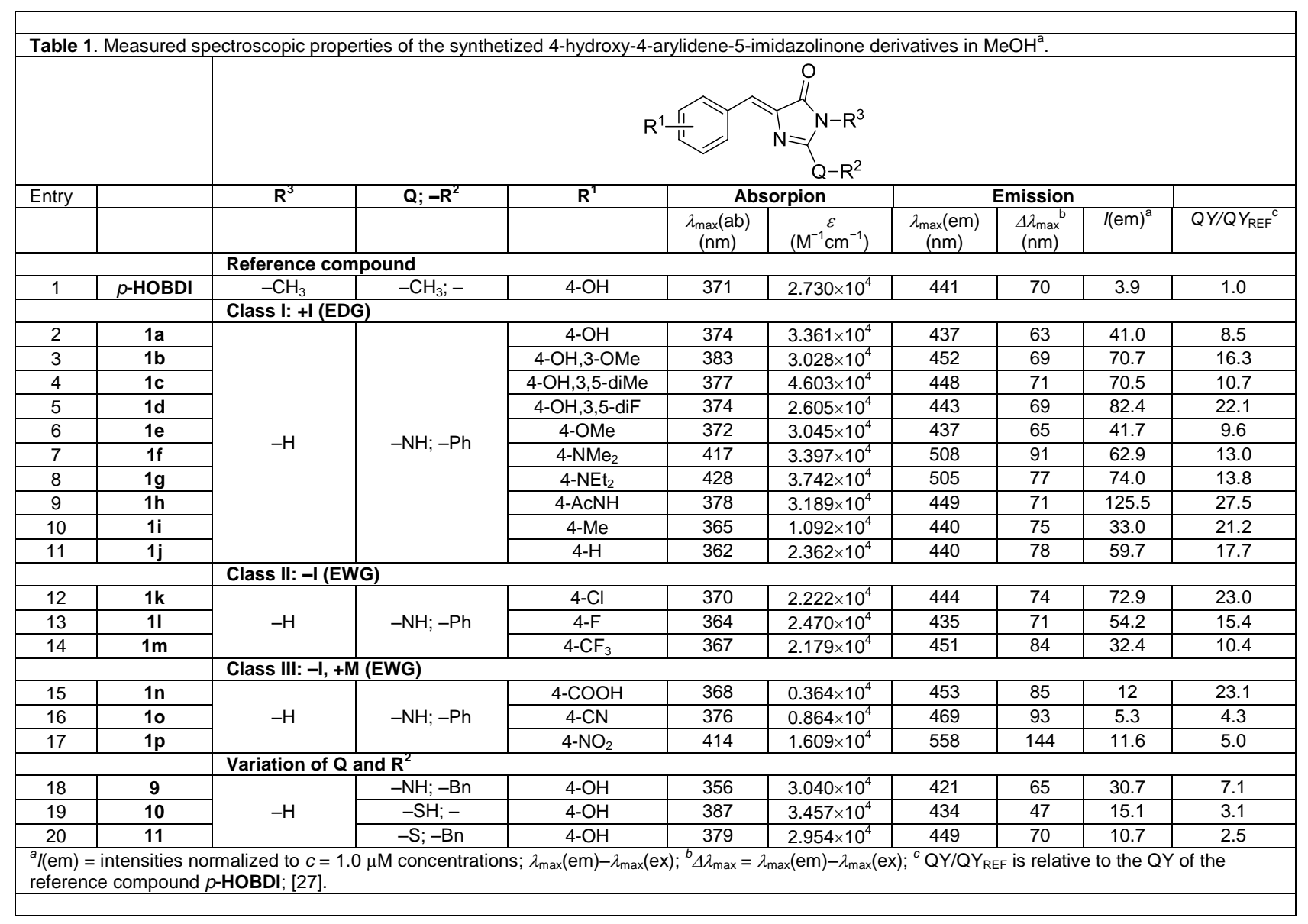

Table 2. Calculated aromaticity percentage for the different aromatic rings (AR1, AR2 and AR3) of the variously substituted molecules (1j, 1f, 1m and $1 p)$ in their different states. All computations were done at B3LYP/6-31G(d,p) level of theory.

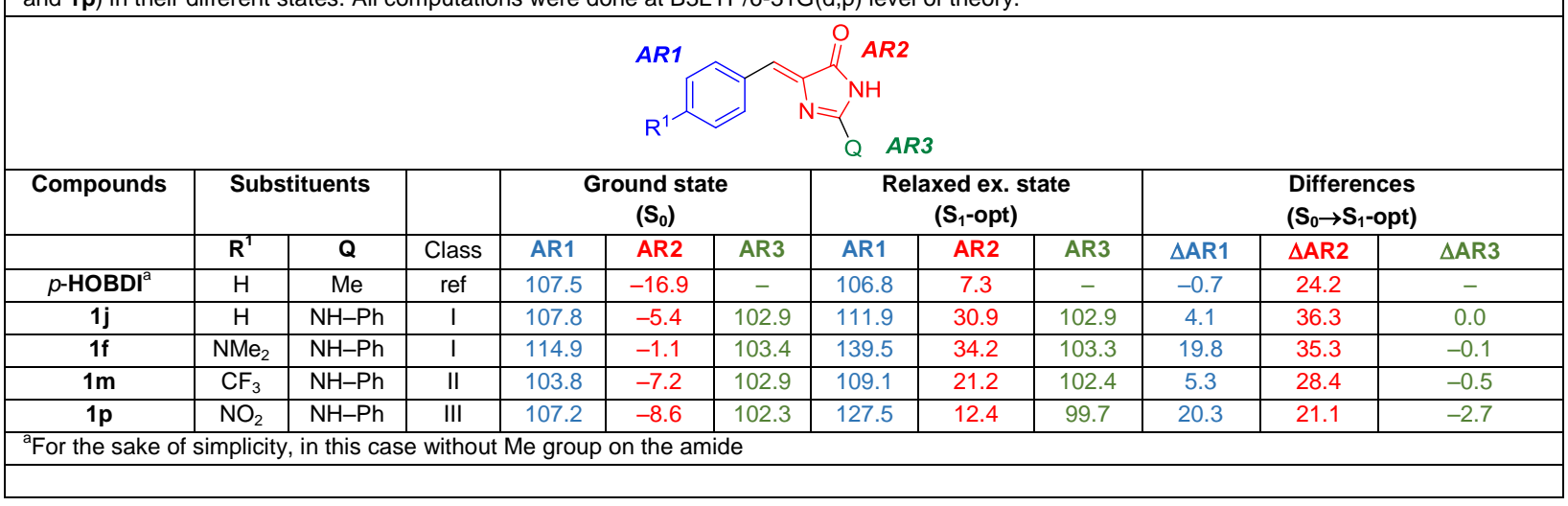


Supplementary Material
Click here to download Supplementary Material: AJancso_Spectrochimica_A_Supl_Material.pdf

Supplementary Material
Click here to download Supplementary Material: AJancso_Spectrochimica_A_Supl_Material.pdf

\begin{abstract}
Che here to download Supplementary Material: AJancso_Spectrochimica_A_Supl Material.pdf
\end{abstract}

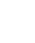

f

